Int. J. Dev. Biol. 54: 1213-1228 (2010)

doi: $10.1387 /$ ijdb.093028sl

\title{
Zebrafish epiboly: mechanics and mechanisms
}

\author{
STEPHANIE E. LEPAGE and ASHLEY E.E. BRUCE* \\ Department of Cell and Systems Biology, University of Toronto, Toronto, ON, Canada
}

\begin{abstract}
Gastrulation involves of a series of coordinated cell movements to organize the germ layers and establish the major body axes of the embryo. One gastrulation movement is epiboly, which involves the thinning and spreading of a multilayered cell sheet. Epiboly plays a prominent role in zebrafish gastrulation and studies of zebrafish epiboly have provided insights into basic cellular properties and mechanisms of morphogenesis that are widely used in animal development. Although considerable progress has been made in identifying molecules that are required for epiboly, we still understand very little about how these factors cooperate to drive the process. Here, we review work on the molecular and cellular basis of zebrafish epiboly in order to identify unifying themes and to highlight some of the current open questions.
\end{abstract}

KEY WORDS: epiboly, morphogenesis, gastrulation, zebrafish, teleost, cell adhesion, radial intercalation

\section{Introduction}

Through the course of early development, a series of regulated cell movements is required to set up the adult body plan of an organism. Collectively referred to as gastrulation, these coordinated cell movements organize the germ layers and establish the major body axes of the embryo. Distinct movements are associated with gastrulation including epiboly, the thinning and spreading of a multilayered cell sheet; involution/ingression, the internalization of mesodermal and endodermal precursors; and convergent extension, the mediolateral intercalation of cells to narrow and extend the embryonic axis.

First described in the teleost fish Cyprinusby von Baer in 1835, epiboly was defined as the overgrowth of the yolk by the blastoderm (reviewed in Betchaku and Trinkaus, 1978). Since then it has been found that many species undergo an epibolic process during development (Kane and Adams, 2002). The term epiboly has now been adopted to describe the thinning and spreading of a sheet of cells, usually ectoderm, to cover the embryo during gastrulation (Gilbert, 2003). The animal region of amphibian gastrulae, for example, undergoes epiboly to expand the surface area of the ectoderm and close the blastopore (Keller, 1980). Similarly, the hypoblast of the $C$. elegans embryo moves ventrally by epiboly to close the blastopore (Williams-Masson etal., 1997). In the chicken embryo, epiboly describes the migration of ectodermal cells along the vitelline envelope to engulf the yolk cell, a process unrelated to gastrulation (Downie and Pegrum, 1971). In mammalian embryos, it has been proposed that trophectoderm spreading during implantation is analogous to epiboly (Kane and Adams, 2002).

An unresolved question is whether epiboly in different species is an evolutionarily conserved process. More information about the cellular and molecular mechanisms driving epiboly in different systems and tissue types is required to answer this important question. Despite this, investigation of teleost epiboly has and is likely to continue to provide insights into fundamental cellular properties and mechanisms of morphogenesis that are widely used throughout animal development. The zebrafish, Danio rerio, has emerged as a vital model system for investigating the molecular mechanisms that drive the coordinated spreading of tissues in the early embryo due to its external development, large size, optical clarity, and genetic tractability. Zebrafish epiboly is initiated prior to the other cell movements of gastrulation (Warga and Kimmel, 1990) making it possible to study its initial events in isolation from later, more complex cell movements.

Progress has been made in identifying individual molecules that are required for zebrafish epiboly, yet, how these factors cooperate to drive the process remains unclear. However, common themes have arisen that have established a solid framework to build upon. Of the factors implicated in epiboly, the majority are cell adhesion components and regulators of cell adhesion and

\footnotetext{
Abbreviations used in this paper: EVL, enveloping layer; F-actin, filamentous actin; FGF, fibroblast growth factor; MO, morpholino; YCL, yolk cytoplasmic layer; YSL, yolk syncytial layer; YSN, yolk syncytial nuclei.
}

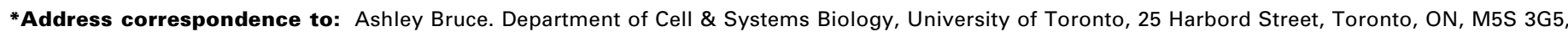
Canada. Lab Phone: +1-416-946-0436. Fax: +1-416-978-8532. Web: http://labs.csb.utoronto.ca/bruce - e-mail:ashley.bruce@utoronto.ca
} 


\section{S.E. Lepage and A.E.E. Bruce}

TABLE 1

\section{SUMMARY OF MOLECULES IMPLICATED IN EPIBOLY}

\begin{tabular}{|c|c|c|c|c|c|}
\hline Protein/ Target & Expression & Mutation/Construct/ Treatment & $\mathrm{I} / \mathrm{P}$ & Phenotype & Reference \\
\hline \multicolumn{6}{|l|}{ Cytoskeleton } \\
\hline \multirow[t]{4}{*}{ Microtubules } & $\mathrm{N} / \mathrm{A}$ & $\begin{array}{l}\text { UV irradiation at } 1 \text {-cell stage }(20-40 \\
\text { minutes post-fertilization) }\end{array}$ & I \& P & $\begin{array}{l}\text { Delayed initiation and progression of epiboly. Yolk cell microtubules } \\
\text { disorganized and reduced in number. }\end{array}$ & Strähle and Jesuthasan, 1993 \\
\hline & $\mathrm{N} / \mathrm{A}$ & $\begin{array}{l}\text { Nocodazole treatment }(0.6-2.0 \mu \mathrm{g} / \mathrm{ml}) \\
\text { at } 16-128 \text {-cell stage, } 10 \text { minutes }\end{array}$ & I \& P & Phenocopied UV irradiated embryos (see above). & Strähle and Jesuthasan, 1993 \\
\hline & N/A & $\begin{array}{l}\text { Nocodazole }(0.5-20 \mu \mathrm{g} / \mathrm{ml}) \text { at late } \\
\text { blastula, } 30 \mathrm{~min} \text { to } 1 \mathrm{hour}\end{array}$ & $\mathrm{P}$ & $\begin{array}{l}\text { YSL contraction/YSN crowding inhibited and epiboly progression delayed. } \\
\text { Disorganized yolk and blastoderm MTs ( } 30 \text { min treatment) or MTs were } \\
\text { destroyed ( } 1 \mathrm{hr} \text { ). } 1 \mathrm{hr} \text { treatment inhibited cell division, involution and } \\
\text { convergence movements. YSN progression blocked at } 40 \% \text {, whereas deep } \\
\text { cells and EVL were delayed. Deep cell margin at } 40 \% \text { and EVL at } 55-60 \% \\
\text { epiboly when controls at } 80 \% \text { epiboly. }\end{array}$ & $\begin{array}{l}\text { Solnica-Krezel and Driever, } \\
1994\end{array}$ \\
\hline & $\mathrm{N} / \mathrm{A}$ & $\begin{array}{l}\text { Taxol }(100 \mu \mathrm{M}) \text { from sphere stage } \\
\text { onward }\end{array}$ & $\mathrm{P}$ & $\begin{array}{l}\text { YSN, deep cells and EVL epiboly delayed to a similar extent. When controls } \\
\text { were at } 60 \% \text {, treated embryos at approximately } 48 \% \text {. Yolk MTs appeared } \\
\text { more dense. }\end{array}$ & $\begin{array}{l}\text { Solnica-Krezel and Driever, } \\
1994\end{array}$ \\
\hline \multirow[t]{3}{*}{ Microfilaments } & $\mathrm{N} / \mathrm{A}$ & $\begin{array}{l}\text { Cytochalasin D }(1-4 \mu \mathrm{g} / \mathrm{ml}) \text { at } 30-50 \% \\
\text { epiboly, } 2 \text { hours }\end{array}$ & $P$ & EVL \& deep cell dissociation, actin fragmentation in EVL, yolk cell herniation. & Zalik et al., 1999 \\
\hline & $\mathrm{N} / \mathrm{A}$ & $\begin{array}{l}\text { Dihydrocytochalasin B }(1-2 \mu \mathrm{g} / \mathrm{ml}) \text { at } \\
30-50 \% \text { epiboly, } 2 \text { hours }\end{array}$ & $\mathrm{P}$ & Phenocopied embryos treated with cytochalasin D (see above). & Zalik et al., 1999 \\
\hline & N/A & $\begin{array}{l}\text { Cytochalasin B }(10 \mu \mathrm{g} / \mathrm{mL}) \text { at } 50 \% \\
\text { epiboly }\end{array}$ & $\mathrm{P}$ & $\begin{array}{l}\text { Dose-dependent epiboly delay, failed blastopore closure, yolk lysis. Greatest } \\
\text { effect on deep cells. }\end{array}$ & Cheng et al., 2004 \\
\hline \multicolumn{6}{|c|}{ Cell adhesion proteins } \\
\hline Cdh1 & $\mathrm{MZ}$ & $\begin{array}{l}\text { Mutants and MO (translation and splice } \\
\text { blocking) }\end{array}$ & eP & $\begin{array}{l}\text { Delayed epiboly of deep cells only. Mild convergence delay. Deep cell radial } \\
\text { intercalation defective, adhesion between outer deep cells and basal surface } \\
\text { of EVL cells compromised. }\end{array}$ & $\begin{array}{l}\text { Babb \& Marrs, 2004; Kane et } \\
\text { al., 2005; Montero et al., 2005; } \\
\text { Shimizu et al., } 2005\end{array}$ \\
\hline ЕрСАM & $\begin{array}{l}M Z \text {, exclusively } \\
\text { in the } E V L \text { during } \\
\text { gastrulation }\end{array}$ & MZ mutants & $\mathrm{P}$ & $\begin{array}{l}\text { Epiboly delay of deep cells and EVL. Tight junctions basally expanded and } \\
\text { reduced membrane localized Cdh1 in EVL cells. Acts partially redundantly } \\
\text { with Cdh1 to maintain EVL integrity and promote deep cell epiboly. }\end{array}$ & Slanchev et al., 2009 \\
\hline Pcdh18a & Z & $\begin{array}{l}\text { Translation blocking MO, } \\
\text { pcdh18a RNA }\end{array}$ & $P$ & $\begin{array}{l}\text { ATG MO - majority of embryos delayed relative to controls; UTR MO - } \\
\text { embryos at } 40-50 \% \text { when controls are } 60-70 \% \text {; RNA - embryos at approx } \\
80 \% \text { when controls reached } 95 \% \text { epiboly. }\end{array}$ & Aamar \& Dawid, 2008 \\
\hline Prpns1 & $M Z$ & Translation blocking MO & $P$ & $\begin{array}{l}\text { Deep cells epiboly impaired, cells shed. E-cad trafficking abnormal, abnormal } \\
\text { radial intercalation. }\end{array}$ & Málaga-Trillo et al., 2009 \\
\hline Celsr2, $a$ and $b$ & MZ & MZord/celsr2 plus splice blocking MOs & $P$ & $\begin{array}{l}\text { Fail to close blastopore, delayed CE, EVL cell shape abnormal. Deep cells } \\
\text { more delayed than EVLs. }\end{array}$ & Carreira-Barbosa et al., 2009 \\
\hline Cldn E & $M Z$ & Translation blocking MO & $\mathrm{P}$ & $\begin{array}{l}\text { Epiboly delay due to reduced adhesion between marginal EVL cells and the } \\
\text { E-YSL. }\end{array}$ & Siddiqui et al., 2010 \\
\hline \multicolumn{6}{|l|}{ Scaffold Proteins } \\
\hline Amotl2 & $M Z$ & Translation blocking MO & $I \& P$ & $\begin{array}{l}\text { Epiboly delay, reduced doming, extension defects, dorsalized. Cell migration } \\
\text { defect }\end{array}$ & Huang et al., 2007 \\
\hline Diaph2 & $M Z$ & Splice-blocking MO & $\mathrm{P}$ & $\begin{array}{l}\text { Late epiboly arrest at } 80-90 \% \text { epiboly, affecting the EVL and deep cells. Mild } \\
\text { convergent extension defects, marginal actin ring reduced. }\end{array}$ & Lai et al., 2008 \\
\hline \multicolumn{6}{|l|}{ Ca2+ regulation } \\
\hline Extracellular $\mathrm{Ca}^{2+}$ & & EGTA (20 mM, 40 min.) & $\mathrm{P}$ & EVL and deep cell dissociation, yolk cell herniation, EVL cortical actin intact. & Zalik et al., 1999 \\
\hline YSL $\mathrm{Ca}^{2+}$ & & $\begin{array}{l}\text { 5-5'-Dibromo-BAPTA (injected at } \\
\text { blastoderm margin, shield) }\end{array}$ & & $\begin{array}{l}\text { Epiboly arrest. Formation of marginal EVL/deep cell actin rings disrupted and } \\
\text { actin puncta in E-YSL fail to form. }\end{array}$ & Cheng et al., 2004 \\
\hline \multicolumn{6}{|l|}{ Kinases } \\
\hline Yes kinase & $\mathrm{MZ}$ & Translation blocking MO & I & $\begin{array}{l}\text { Epiboly arrest, nuclear abnormalities, DV patterning defects, endodermal } \\
\text { markers not expressed. }\end{array}$ & Tsai et al., 2005 \\
\hline Fyn kinase & $\mathrm{MZ}$ & DN constructs & I & $\begin{array}{l}\text { Arrested at sphere, marginal calcium activity blocked. Expression of mezzo } \\
\text { (endoderm marker) more diffuse. }\end{array}$ & Sharma et al., 2005 \\
\hline Mapk1 & MZ & Translation blocking MO & 1 & $\begin{array}{l}\text { Arrest at sphere or severe epiboly delay. Irregular YSN narrowing, mesoderm } \\
\text { specification defects, and extension defects. }\end{array}$ & $\begin{array}{l}\text { Krens et al., 2008; } \\
\text { Krens et al., } 2006\end{array}$ \\
\hline Mapkapk2 & MZ & betty boop (maternal effect) & $\mathrm{P}$ & $\begin{array}{l}\text { All embryos undergo fatal constriction of blastoderm margin at } 50 \% \text { epiboly. } \\
\text { Abnormal calcium dynamics. Primary defect in yolk cell. }\end{array}$ & $\begin{array}{l}\text { Wagner et al., 2004; } \\
\text { Holloway et al., } 2009\end{array}$ \\
\hline Tnika & $\mathrm{MZ}$ & Splice-blocking MO & $\mathrm{P}$ & $\begin{array}{l}\text { Epiboly defects visible at } 65 \% \text { epiboly, which are the result of aberrant cell } \\
\text { shape changes in marginal EVL cells. In addition, convergent extension and } \\
\text { axial defects. }\end{array}$ & Köppen et al., 2006 \\
\hline \multicolumn{6}{|c|}{ Transcriptional regulation } \\
\hline Pou5f1 & $\begin{array}{l}\text { MZ, ubiquitously } \\
\text { early and } \\
\text { restricted to the } \\
\text { epiblast during } \\
\text { gastrulation }\end{array}$ & spiel ohne grenzen (Mspg, \& MZspg) & $I \& P$ & $\begin{array}{l}\text { Doming and epiboly delay, dorsalized, lack endoderm. MZspg initially have } \\
\text { delayed deep cells then arrest around the onset of gastrulation. Mspg } \\
\text { embryos experience the early delay in epiboly but eventually recover and } \\
\text { complete epiboly. }\end{array}$ & $\begin{array}{l}\text { Lachnit et al, 2008; Reim \& } \\
\text { Brand, } 2006\end{array}$ \\
\hline Eomesa & $M Z$ & DN constructs & I & Doming and epiboly delay. & Bruce et al., 2005 \\
\hline Mxtx2 & z & Translation blocking MO & $\mathrm{P}$ & $\begin{array}{l}\text { Epiboly arrest and subsequent yolk cell lysis towards the middle of epiboly. } \\
\text { Yolk cell defects, actin ring abnormal, and convergence delay. }\end{array}$ & $\begin{array}{l}\text { Bruce et al., } 2005 \\
\text { Wilkins et al., } 2007\end{array}$ \\
\hline IRF6 & $\mathrm{MZ}$ & DN contructs & $\mathrm{P}$ & $\begin{array}{l}\text { Epiboly of the deep cells, EVL and YSL was disrupted with defects first } \\
\text { becoming apparent around dome stage. }\end{array}$ & Sabel et al., 2008 \\
\hline FoxH1 & MZ & Translation blocking MO & $P$ & $\begin{array}{l}\text { Epiboly and developmental delay were apparent by } 6 \mathrm{hpf} \text { and embryos died } \\
\text { by } 14-17 \mathrm{hpf} \text {. Internalization defect and defect in EVL differentiation. }\end{array}$ & Pei et al., 2007 \\
\hline \multicolumn{6}{|l|}{ Glycosylation } \\
\hline $\begin{array}{l}\text { O-GlcNAc } \\
\text { transferase (Ogt, } \\
\text { catalyzes } \\
\text { attachment of O- } \\
\text { GlcNAc to target } \\
\text { proteins) }\end{array}$ & $\mathrm{MZ}$ & RNA & $P$ & $\begin{array}{l}\text { Arrested epiboly at } 40 \% \text { epiboly. The epiboly delay correlated with shorter, } \\
\text { thicker and abnormally organized yolk microtubules. The marginal actin band } \\
\text { was absent in severely affected embryos and there were defects in the } \\
\text { morphology of EVL cells. } \\
\text { Aberrant germ layer specification. }\end{array}$ & Webster et al., 2009 \\
\hline
\end{tabular}


TABLE 1 (CONTINUED)

\section{SUMMARY OF MOLECULES IMPLICATED IN EPIBOLY}

\begin{tabular}{|c|c|c|c|c|c|}
\hline \multicolumn{6}{|c|}{ Prostaglandin (PGE(2)) biosythesis } \\
\hline \multirow{2}{*}{ Cox-1 } & \multirow{2}{*}{$\mathrm{MZ}$} & $\begin{array}{l}\text { Indomethacin treatment }(25-50 \mu \mathrm{M}) \text { at } \\
2-8 \text { cell }\end{array}$ & $P$ & $\begin{array}{l}\text { Indomethacin }(50 \mu \mathrm{M}) \text { caused epiboly arrest at } 50 \% \text {, delay at lower doses. } \\
\text { Epiboly defects can be rescued by co-incubating embryos in } \mathrm{PGE}_{2} \text {. }\end{array}$ & Cha et al., 2005 \\
\hline & & Translation blocking MO & $P$ & $\begin{array}{l}\text { Epiboly arrest at approximately } 50 \% \text { at high } \mathrm{MO} \text { doses. Epiboly delayed if } \\
\text { lower dose administered. }\end{array}$ & Grosser et al., 2002 \\
\hline Ptges & $\mathrm{MZ}$ & $\begin{array}{l}\text { Translation blocking and splice } \\
\text { blocking MO }\end{array}$ & $P$ & Slow epiboly or gastrulation arrest, CE defects. & Cha et al., 2006 \\
\hline \multicolumn{6}{|l|}{ Miscellaneous } \\
\hline Cyp11a1 & $\begin{array}{l}\text { MZ ubiquitous } \\
\text { during cleavage, } \\
\text { YSL restricted } \\
\text { during epiboly }\end{array}$ & Translation blocking MO & $\mathrm{P}$ & $\begin{array}{l}\text { Slight epiboly delay and blastopore closure defect, CE defects. Yolk MTs less } \\
\text { stable. }\end{array}$ & Hsu et al., 2006 \\
\hline B4.1 and B4.2 & $\mathrm{MZ}$ & Splice blocking MO & I & $\begin{array}{l}\text { Most severe fail to dome, marginal cell death, yolk lysis when controls at } \\
50 \% \text {. YSN morphology abnormal. } \mathrm{Ca}^{2+} \text { channel-independent function. }\end{array}$ & Ebert et al., 2008 \\
\hline $\mathrm{G} \alpha_{12 / 13}$ & $\mathrm{MZ}$ & RNA, DN and translation blocking $\mathrm{MO}$ & $\mathrm{P}$ & $\begin{array}{l}\text { CE, deep cell epiboly delay, blastopore closure delayed, multiple small dfc } \\
\text { clusters, YCL abnormalities, EVL cells fail to undergo normal shape changes. }\end{array}$ & Lin et al, 2009 \\
\hline Chimerin1 & $M Z$ & Translation blocking MO & $P$ & $\begin{array}{l}\text { Slightly quicker epiboly of deep cells, YSL and EVL with a larger than normal } \\
\text { accumulation of cells in the tailbud once epiboly was complete. }\end{array}$ & Leskow et al, 2006 \\
\hline Lefty 1 and 2 & z & Translation blocking MO & $P$ & $\begin{array}{l}\text { Epiblast fails to differentiate properly. Expanded hypoblast cell fates. } \\
\text { Excessive internalization around the whole margin. }\end{array}$ & Feldman et al., 2002 \\
\hline Profilin 1 & $Z$ (in the EVL) & Translation blocking MO & $P$ & Mild epiboly and CE defects. Shown to act synergistically with Diaph2. & Lai et al., 2008 \\
\hline Myosin 2 & Z & $\begin{array}{l}50 \mu \mathrm{m}( \pm) \text {-blebbistatin } \\
\text { after } 50 \% \text { epiboly }\end{array}$ & $\mathrm{P}$ & $\begin{array}{l}\text { Epiboly delayed or arrested. Other aspects of gastrulation not significantly } \\
\text { affected. }\end{array}$ & Köppen et al., 2006 \\
\hline \multicolumn{6}{|c|}{ Unmapped maternal effect epiboly mutants } \\
\hline unknown & M & poky & $\mathrm{P}$ & $\begin{array}{l}\text { Deep cells, YSL and EVL delayed, primarily in late epiboly. Yolk cell } \\
\text { frequently bursts before epiboly is complete. Cell differentiation and other cell } \\
\text { movements not affected. }\end{array}$ & Wagner et al., 2004 \\
\hline unknown & M & slow & $P$ & $\begin{array}{l}\text { Deep cells affected more than YSL and EVL, resembling hab mutants. } \\
\text { Whereas the EVL and YSL usually complete epiboly, deep cells frequently do } \\
\text { not. Cell differentiation and other cell movements not affected. }\end{array}$ & Wagner et al., 2004 \\
\hline unknown & M & bedazzled & $P$ & $\begin{array}{l}\text { Delay is primarily in deep cells and cells shed from the EVL. Convergence } \\
\text { also affected. }\end{array}$ & Wagner et al., 2004 \\
\hline unknown & M & screeching halt & 1 & $\begin{array}{l}\text { Developmental arrest at sphere stage. Abnormal cell divisions and nuclear } \\
\text { fragmentation. Failure to properly initiate zygotic gene expression at MBT. }\end{array}$ & Wagner et al., 2004 \\
\hline
\end{tabular}

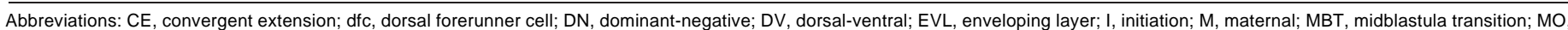
morpholino; MT, microtubules; P, progression; YCL, yolk cytoplasmic layer; YSL, yolk syncytial layer; YSN, yolk syncytial nuclei; Z, zygotic.

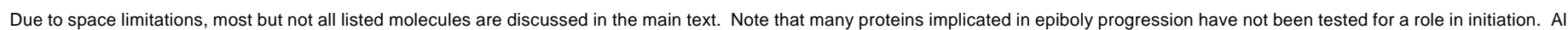
studies using morpholinos included control experiments demonstrating the specificity of the morphant phenotypes.

cytoskeletal dynamics (reviewed in Heisenberg and SolnicaKrezel, 2008; Solnica-Krezel, 2006). Recently, significant new insights into zebrafish epiboly have emerged and, with this comprehensive review, we seek to identify unifying themes that will allow us to begin to piece together the molecular mechanisms controlling epiboly and to address some of the current open questions. For additional details and summary of the work discussed below, please refer to Table 1.

\section{Zebrafish epiboly}

Prior to the onset of epiboly, the embryo is organized into three layers (Fig. 1A). A single-cell thick epithelium, the enveloping layer (EVL), envelops the deep cells that eventually give rise to embryonic tissues. The EVL gives rise to periderm and to dorsal forerunner cells which form Kupffer's vesicle (Oteíza et al., 2008), an organ analogous to the mammalian node (Essner et al., 2005; Kramer-Zucker et al., 2005). The EVL is tightly attached at its margin to the third layer, the yolk syncytial layer (YSL), an extraembryonic syncytium populating the interface between the yolk and deep cells. The YSL forms around cell division 10 (3 hpf, midblastula transition), when marginal blastomeres fuse with and deposit their nuclei into the cortex of the underlying yolk cell (Kimmel and Law, 1985). YSL nuclei (YSN, Fig. 1) undergo several more rounds of mitosis, and typically exit the cell cycle at division 14 (Kane et al., 1992). Initially, the YSN form a wide belt at the periphery of the blastoderm margin, the external-YSL (EYSL), but by sphere stage (4 hpf) the YSN distribute beneath the blastoderm, forming the internal-YSL (I-YSL) (Kimmel et al., 1995). With the formation of the YSL, the yolk becomes a region of active gene expression and signaling, with gap junction connections to the overlying blastoderm (Kimmel and Law, 1985). All three embryonic layers undergo epiboly, thus zebrafish epiboly can serve as a model for studying the movement of individual or small groups of cells (blastoderm), spreading of an epithelial sheet (EVL) and movements of a syncytium (YSL).

\section{Epiboly initiation - doming}

Much of our early knowledge regarding the mechanics of zebrafish epiboly comes from studies by J. P. Trinkaus and colleagues on the teleost Fundulus heteroclitus, which shares many developmental features with the zebrafish. In both organisms, epiboly can be considered a two-phase process (Betchaku and Trinkaus, 1978; Strähle and Jesuthasan, 1993). The first phase, initiation, encompasses the transition from sphere stage (4 hours post-fertilization, hpf) to dome stage (4.3 hpf, Fig. $1 \mathrm{~A}, \mathrm{~B}$ ) and the major cell movement during this transition is radial intercalation (Warga and Kimmel, 1990).

At sphere stage, the blastoderm, once piled high atop the rounded yolk, is compressed downwards, the blastoderm-yolk 
interface flattens and the embryo assumes a spherical shape (Fig. 1A). At this time, the EVL becomes lineage restricted (Kimmel et al., 1990). In Fundulus, the EVL is held taut by tight junction attachments to the YSL, such that severing the connection between the EVL margin and YSL causes the EVL to retract towards the animal pole (Trinkaus, 1951). The situation appears to be similar in zebrafish and increased tension within the EVL may act to maintain the lineage by keeping mitotic spindles oriented in the plane of the cell sheet (Kane and Adams, 2002; Kimmel et al., 1990). During doming, the E-YSL contracts along the animal-vegetal axis, causing the YSN to crowd (SolnicaKrezel and Driever, 1994). Concurrently, the yolk cell rounds upwards into the overlying blastoderm (Fig. 1B) such that the blastoderm thins and forms an inverted cup on top of the yolk cell (Warga and Kimmel, 1990). The mechanism by which the flat yolk-blastoderm interface domes is not understood.

Deep cells become motile around the midblastula transition, exhibiting blebs and moving in random directions until the onset of epiboly when cells move radially outward (Kane and Kimmel, 1993; Warga and Kimmel, 1990). Although individual cell trajectories have not been analyzed, it has been shown that by early gastrulation, differentially labeled deep and superficial cell clones become wholly interspersed in a pattern suggestive of radial movement (Warga and Kimmel, 1990). Between dome and 30\% epiboly stages, the greatest amount of cell dispersion occurs in the central region of the embryo (Wilson et al., 1995). Although it has never been directly tested, these findings have led to the prevalent view that deep cells are passively pushed outwards by the doming yolk cell (Wilson et al., 1995). Regardless of whether deep cells move actively or passively, cell motility is a permissive requirement for epiboly to initiate.

Although the majority of factors implicated in doming are maternally expressed, zygotic transcription is required, as embryos fail to dome when treated with the transcriptional inhibitor $\alpha$ amanitin during cleavage stages (Kane et al., 1996). Despite this link between zygotic transcription and epiboly initiation, no zygotic mutants with specific defects in doming have been recovered (Kane et al., 1996). Even more intriguing is that only one mutant that fails to dome was recovered from recent maternal screens
(Dosch et al., 2004; Wagner et al., 2004). screeching halt (srh) embryos exhibit defects in cell division as well as abnormalities in the coordinated activation of zygotic gene expression at MBT (Wagner et al., 2004). At sphere stage, srh embryos arrest development and, as such, fail to undergo any morphogenetic movements. The morphogenesis defects, therefore, are most likely the secondary consequence of the failure to properly execute zygotic gene expression. Although saturation has not been achieved for either screen, the most likely explanation for the paucity of epiboly initiation mutants is that there is redundancy in the mechanisms that initiate epiboly.

\section{Epiboly progression}

The largest increase in blastoderm surface area occurs during epiboly progression which begins with the completion of doming and continues until the blastopore closes at the vegetal pole (4.3 $-10 \mathrm{hpf}$, Fig. 1C-E). During this phase, stages are defined by the percentage of yolk surface that is covered by the spreading blastoderm. The relative positions of the deep cell, EVL and YSL margins dynamically change throughout the course of epiboly progression; however, the tightly attached YSL and EVL are always located vegetal to the blastoderm margin (Solnica-Krezel and Driever, 1994). Between $30 \%$ and $40 \%$ epiboly, the E-YSN progressively become covered by the blastoderm (Solnica-Krezel and Driever, 1994). At 50\% epiboly (Fig. 1D), the blastoderm expands to engulf the widest part of yolk and shortly after, deep cell epiboly temporarily ceases as the other movements of gastrulation are initiated (Solnica-Krezel and Driever, 1994; Warga and Kimmel, 1990). This lag in deep cell epiboly allows the EVL and YSL to extend past the blastoderm margin such that the EVL and YSL cover $65 \%$ and $70 \%$ of the yolk surface, respectively, when the deep cells have reached $60 \%$ epiboly (Solnica-Krezel and Driever, 1994). As a result of internalization, the deep cells become organized into two layers - an outer ectodermal epiblast and an inner mesendodermal hypoblast (Fig. 1E). Unlike initiation, which occurs in isolation from other gastrulation movements, the majority of the progression phase is concurrent with ingression and convergence. Once the blastoderm has spread beyond the equator of the yolk, the margin begins to constrict circumferentially, closing the blasto-
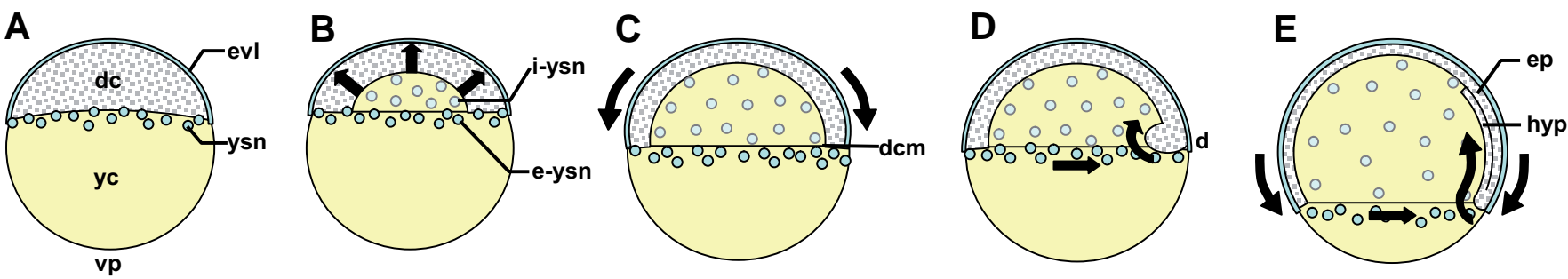

4 hpf

initiation

$4.3 \mathrm{hpf}$

progression

$10 \mathrm{hpf}$

Fig. 1. Schematic depiction of epiboly initiation and progression in the zebrafish embryo. (A) At sphere stage, the EVL and YSL have been created and the deep cells form a flat interface with the underlying yolk cell. (B) Upon epiboly initiation, the yolk cell domes and deep cells move radially outwards, forming a cap of cells over the yolk. (C-E) During the progression phase, the blastoderm continues to thin, expanding its surface area to envelop the yolk cell. (D) Once the blastoderm has covered approximately $50 \%$ of the yolk, deep cell epiboly temporarily pauses as cells begin to converge dorsally and gastrulation begins. (E) Concurrent with the other gastrulation movements, the deep cells, EVL and YSL move towards the vegetal pole in a coordinated manner, eventually closing the blastopore. Deep cells are shown in white, the EVL and YSL in blue and the yolk cell is shown in yellow. Black arrows indicate general direction(s) of organized cell movement. d, dorsal; dc, deep cells; dcm, deep cell margin; e-ysn, external yolk syncytial nuclei; ep, epiblast; hyp, hypoblast; i-ysn, internal yolk syncitial nuclei; vp, vegetal pole; yc, yolk cell. 

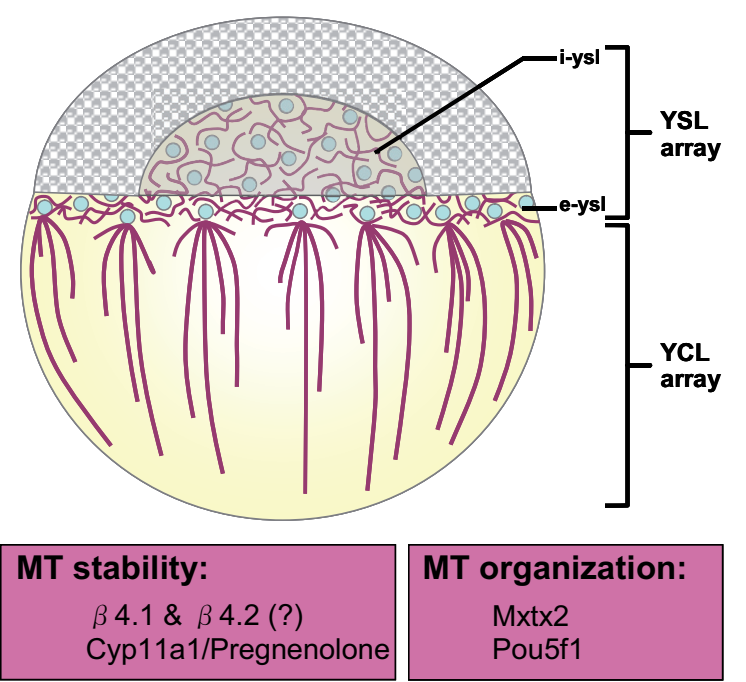

Fig. 2. Organization of yolk cell microtubule arrays. Microtubules (purple) form a meshwork between the nuclei of the internal and external YSL. A second microtubule array is localized to the YCL. Long microtubule bundles extend from organizing centres located in close proximity to the vegetal-most YSN towards the vegetal pole. Factors affecting microtubule stability and organization during epiboly are listed in boxes below (see text and Table 1 for details). The question mark indicates that it is currently unclear whether $\beta 4.1$ and $\beta 4.2$ directly regulate microtubule stability. Blastoderm is illustrated in grey, yolk in yellow, and YSN in blue. Figure adapted from Solnica-Krezel and Driever (1994).

pore (Cheng et al., 2004).

\section{The yolk cell - an epiboly motor?}

The yolk cell plays a fundamental role in epiboly. In Fundulus, the YSL undergoes epiboly at an accelerated rate when the blastoderm is removed from the yolk cell, suggesting that the yolk cell normally pulls the EVL and deep cells along with it (Betchaku and Trinkaus, 1978; Trinkaus, 1951). The YSL likely exerts its pulling force on the blastoderm via its tight junction connections to the EVL margin. Consistent with the yolk cell acting as an epiboly motor is the observation that dynamic changes in the yolk surface and cytoskeleton coincide with epiboly progression.
The yolk cell membrane is dramatically modified during the progression phase, such that $87 \%$ of the external membrane is removed between shield stage and the end of epiboly in zebrafish (Cheng et al., 2004). In both Fundulus and zebrafish, the external yolk cell membrane is likely recovered by a region of active endocytosis, located just vegetal to the advancing blastoderm margin (Betchaku and Trinkaus, 1986; Solnica-Krezel and Driever, 1994). Although marginal endocytosis may contribute to driving epiboly progression (Solnica-Krezel and Driever, 1994), the consequence of blocking this process has not been examined. While exposed yolk membrane is removed during the progression phase, the surface area of the I-YSL membrane must expand considerably. In Fundulus, the I-YSL membrane is covered with long microvilli sufficient to provide the required surface area to complete epiboly and these microvilli shorten over the course of epiboly (reviewed in Trinkaus, 1984). It is not known whether the I-YSL membrane (Carvalho etal., 2009) expands by a similar mechanism during zebrafish epiboly.

Both the microtubule and actin cytoskeleton are critical for normal epiboly. Prior to doming, microtubules form a dense meshwork around the YSN and a second array is present in the yolk cytoplasmic layer (YCL, Fig. 2), a thin layer of cytoplasm that surrounds the central yolk mass and is contiguous with the YSL (Solnica-Krezel and Driever, 1994). The YCL microtubules emanate from microtubule organizing regions, located in close proximity to the vegetal-most YSN, and extend towards the vegetal pole. The observation that YCL microtubules shorten over the course of epiboly suggested that they might be responsible for towing the blastoderm vegetally (Solnica-Krezel and Driever, 1994).

Beginning at high stage, filamentous actin (F-actin) forms a cortical belt around each cell of the EVL (Fig. 3, Zalik et al., 1999). Two distinct rings of $\mathrm{F}$-actin can be found along the margin during late epiboly. One is observed along the leading edge within marginal EVL and deep cells. Vegetal to the leading edge, a second, punctate ring of actin is also present in the E-YSL, the area corresponding to the region of marginal endocytosis (Cheng et al., 2004). Together, these rings are involved in mediating the circumferential constriction of the margin during late epiboly to close the blastopore (Cheng et al., 2004). F-actin is also present in the vegetal cortex throughout epiboly where it likely provides structural integrity to the yolk cell (Cheng et al., 2004). The functional
Fig. 3. F-actin organization at the margin during epiboly progression. Circumferential actin rings are located at the deep cell and EVL margins. A punctate actin ring is present just ahead of the leading edge, in the E-YSL, where marginal endocytosis takes place. Localized myosin-dependent contractions of the punctate actin ring are thought to drive shape changes in adjacent EVL cells, causing the margin to constrict. Additionally, actin forms cortical belts at the periphery of each

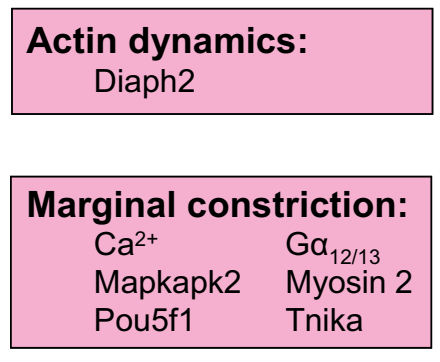

\section{Actin organization:}

Mxtx2

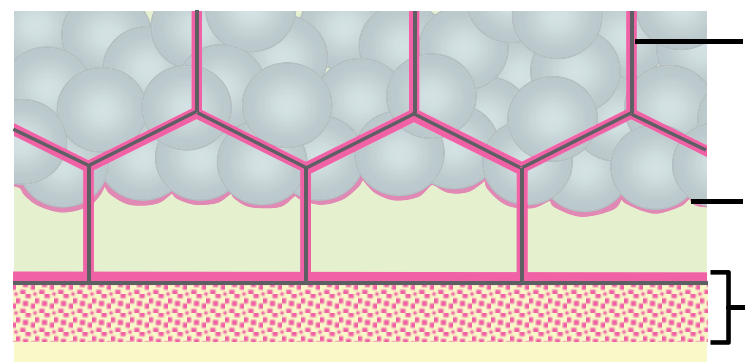

EVL cortical actin belt
EVL cell and diffusely covers the cortex of the exposed yolk, where it helps to maintain tissue integrity. Schematic shows a magnified view of the blastoderm margin. Actin is shown in pink, yolk in yellow and deep cells in grey. Factors known to affect actin dynamics, marginal constriction and actin organization during epiboly are listed in boxes to the left (see text and Table 1 for details). 
consequences of perturbing either the microtubule or actin cytoskeleton are discussed in further detail below.

\section{Dynamics of microtubule arrays}

The necessity for dynamic regulation of yolk cell microtubules was initially demonstrated by Strähle and Jesuthasan (1993) who showed that disrupting microtubules with UV light or with the depolymerizing agent nocodazole delayed epiboly initiation and progression. UV-irradiated embryos exhibited a sustained disruption of the YCL microtubule array, whereas microtubules in the YSL and deep cells recovered once embryos had initiated epiboly. Taken together, these results suggest that the YCL microtubule array plays a role in controlling the rate of epiboly.

Whether microtubules are required during both the initiation and progression phases of epiboly is unclear. A subsequent study by Solnica-Krezel and Driever (1994) found that nocodazole treatment solely affected epiboly progression. Interestingly, the E-YSL of the nocodazole treated embryos failed to contract prior to initiation; however, embryos successfully domed, suggesting that microtubule-mediated contraction of the YSL is dispensable for initiation. The conflicting results of these two studies likely reflect differences in the timing, dose and/or duration of nocodazole treatment (see Table 1 for details). In the Solnica-Krezel and Driever (1994) study, nocodazole was administered just prior to doming, thus it is not clear whether nocodazole was applied far enough in advance for it to take full effect. Strähle and Jesuthasan (1993), on the other hand, administered nocodazole during cleavage stages. Therefore, it is possible that the effect on doming was secondary to a defect in an earlier microtubule-dependent process such as cell proliferation.

A recent paper proposed that the calcium channel $\beta 4$ subunit, a membrane associated guanylate cyclase, affects doming by regulating the stability of yolk microtubules (Ebert etal., 2008). Zebrafish $\beta 4.1$ and $\beta 4.2$ regulate doming, independent of calcium channel activity. Injection of splice blocking antisense morpholino oligonucleotides $(\mathrm{MO})$ resulted in the most severely affected embryos failing to dome. At a lower frequency, YSL-specific knockdown also blocked epiboly initiation, suggesting $\beta 4.1$ and $\beta 4.2$ genes have autonomous functions in the yolk. They observed a similar phenotype in embryos treated with nocodazole. However, yolk microtubules were not visualized in this study, thus direct evidence is still required to establish that the morphant phenotypes resulted from microtubule defects.

Further evidence demonstrating the importance of yolk cell microtubule stability for epiboly comes from work on Cytochrome P450, subfamily XIA, polypeptide 1 (Cyp11a1) (Hsu et al., 2006). Cyp11a1, an enzyme involved in catalyzing cholesterol into pregnenolone, is expressed ubiquitously during cleavage stages and becomes confined to the YSL during epiboly (Hsu et al., 2002). Global or YSL-specific morpholino knockdown caused a mild epiboly delay and a blastopore closure defect (Hsu et al., 2006). Although the yolk microtubule network appeared to be normal in cyp11a1 morphants, microtubules were less stable, being more susceptible to depolymerization by nocodazole (Hsu et al., 2006). Hsu et al. (2006) demonstrated that dye labeled pregnenolone binds microtubules in zebrafish cell extracts, suggesting it directly interacts with the cytoskeleton; however, the mechanism by which pregnenolone maintains microtubule stability remains to be determined. Notably, epiboly defects also occur when microtubules are too stable, as when embryos are treated with the microtubule stabilizing agent taxol, consistent with the fact that the YCL microtubule array shortens over the course of epiboly (SolnicaKrezel and Driever, 1994).

\section{Actin dynamics}

The actin cytoskeleton is primarily involved in the epiboly progression phase. Treating embryos with the actin-depolymerizing agent cytochalasin at $50 \%$ epiboly leads to delayed epiboly, failed closure of the blastopore, and yolk cell lysis (Cheng et al., 2004). Therefore, actin is important for maintaining yolk membrane integrity and is required for the proper progression and completion of epiboly.

Köppen et al. (2006) examined actin-based shape changes in the EVL layer as the margin constricts to close the blastopore. As an embryo approaches $75 \%$ epiboly, marginal ovoid-shaped EVL cells generally narrow mediolaterally and elongate along the animal-vegetal axis. Concurrently, F-actin condenses, forming rings in the E-YSL and marginal EVL cells. Interestingly, there is considerable variability in this process, with some cells narrowing at the leading edge and others widening, which reflects the local level of actin in the adjacent YSL. These observations suggested that local actin contraction within the YSL underlies shape changes in marginal EVL cells.

Knockdown of zygotic TRAF2 and NCK interacting kinase a, tnika (formerly misshapen 1), a member of the germinal center kinase (GCK) family, disrupted marginal EVL shape change and delayed progression of the EVL and deep cells (Köppen et al., 2006). Injection of splice blocking MO into the YSL was also sufficient to delay deep cell and EVL epiboly, supporting the notion that the YSL non-autonomously affects marginal EVL cell morphology. At $75 \%$ epiboly, YSL-injected morphants failed to form distinct actin rings in the E-YSL and marginal EVL cells. YSL morphants also failed to recruit activated non-muscle Myosin 2, a regulator of actin-based shape change in other systems, to the EVL-YSL interface. In addition, treatment of embryos with the Myosin 2 inhibitor blebbistatin phenocopied tnika morphants (Köppen etal., 2006). These data suggest that Tnika recruits actin and Myosin 2 to the EVL-YSL interface where, together, they generate a circumferential contraction of the E-YSL actin ring. Indirectly, actomyosin contraction in the E-YSL causes local shape changes in the adjacent marginal EVL cells, reducing the circumference of the EVL margin as it progresses towards the vegetal pole (Köppen et al., 2006).

A recent report on the maternal effect epiboly mutant betty boop $(b b p)$ has provided further insight into the regulation of the E-YSL actin ring contraction (Holloway et al., 2009). bbp mutants carry a mutation in mitogen activated protein kinase activated protein kinase 2(mapkapk2) which abolishes its serine-threonine kinase activity (Holloway et al., 2009). In bbp mutant embryos, epiboly is initiated normally but at $50 \%$ epiboly, embryos undergo a premature constriction of the blastoderm margin and fatal yolk cell lysis. Although cytoskeletal organization and marginal endocytosis were normal prior to $50 \%$ epiboly, abnormal movements in the blastoderm, dubbed "shimmying", were apparent. These aberrant movements occurred throughout the blastula period, gaining amplitude until yolk cell lysis. Interestingly, $b b p$ mutants also exhibited ectopic fluxes in calcium and intercellular calcium waves, which propagate along the blastoderm margin 
during blastopore constriction (Holloway et al., 2009). In wild type embryos, marginal constriction occurs slowly over a 3 hour period, while this process was reduced to a mere 20-30 minutes in bbp mutants (Holloway et al., 2009), suggesting that the circumferential actin ring contraction is mis-regulated. It is likely that the excess and ectopic calcium in bbp mutants, contributes to both the precocious activation of actomyosin contraction in the E-YSL and contractions that cause the blastoderm to 'shimmy'.

The Rho family of small GTPases are involved in directly regulating actin dynamics underlying cell motility (for recent review see Ladwein and Rottner, 2008). Small GTPase activity is regulated by guanine exchange factors, which promote the GTPbound active state, and GTPase activating proteins (GAPs), which promote the GDP-bound inactive state. As modification of the actin cytoskeleton is clearly important for epiboly, it is not surprising that Rho and a variety of small GTPases interacting proteins have been linked to epiboly progression.

Work on zebrafish diaphanous homolog 2 (diaph2) indirectly supports a requirement for Rho for epiboly progression. Diaphanous-related formin proteins directly interact with Rho to enhance actin nucleation and have been implicated in morphogenesis, cell shape change and adhesion (reviewed in Goode and Eck, 2007). Zebrafish diaph2, which is expressed ubiquitously throughout gastrulation, directly interacts with activated RhoA and Cdc42 (Lai et al., 2008). Injection of diaph2translation or splice-blocking MOs caused late arrest at $80-90 \%$ epiboly. Actin failed to accumulate at the EVL margin and, consistent with work in other systems demonstrating that Diaphanous is involved in filopodia formation, morphant deep cells displayed a cell autonomous reduction in protrusive activity and slower movements when transplanted into wild type hosts (Lai et al., 2008; Yang et al., 2007).

It has also been shown in other systems that Diaph2 interacts with Profilin, a protein that associates with actin monomers and contributes to actin polymerization and capping (Goode and Eck, 2007). A synergistic impairment of epiboly and convergent extension was observed in zebrafish embryos co-injected with low doses of diaph2 and profilin1 MOs (Lai et al., 2008). Notably, profilin1 is expressed exclusively in the EVL during epiboly (zfin.org), raising the possibility that these two factors cooperate to facilitate epiboly of this layer. As deep cells are restricted from moving beyond the EVL margin, the synergistic impairment of deep cell epiboly and convergent extension observed in diaph2 profilin1 double morphants may be secondary to a defect in EVL epiboly. Further work is needed to determine the nature of the actin defects in diaph2morphant embryos and further analysis of diaph2l profilin1 double morphants is warranted. In addition, it could be informative to examine microtubule organization as formins have been shown to have effects on microtubules in other systems (Goode and Eck, 2007).

Zebrafish chimerin1 (chn1) is a maternally and zygotically expressed lipid-regulated Rac-GAP proposed to play a unique role in epiboly progression (Leskow et al., 2006). Rather than slowing epiboly progression, the deep cells, YSL and EVL of chn1 morphants undergo slightly quicker epiboly, leading to a larger than normal accumulation of cells in the tailbud (Leskow et al., 2006). YSL-specific knockdown of Chn1 led to a similar, though milder, phenotype, suggesting that Chn1 activity is at least partially required in the yolk during epiboly. chn1 morphants had significantly increased levels of activated Rac and injection of
mRNA encoding constitutively active Rac into the YSL of wild type embryos partially phenocopied chn1 morphants (Leskow et al., 2006). The enlarged tailbud in chn 1 morphant embryos suggests that more cells moved vegetally than in wild type embryos, which could be explained by cells moving down to the vegetal pole instead of converging dorsally as they would normally. Thus, whether Chn1 plays a direct role in epiboly is currently unclear. To address this question, it would be informative to examine cell morphologies, speeds and trajectories of movement. As Chn1 activation is tightly regulated in other systems, it will also be of interest to determine what factors act upstream of Chn1.

\section{Cell fate specification as a general prerequisite for epiboly}

Defects in cell fate specification have been shown to indirectly affect epiboly. The Nodal signaling pathway plays a critical role in germ layer specification and Nodal-mediated cell fate specification influences epiboly progression. Embryos injected with morpholinos to the transcription factor Foxh1, a co-factor to the Smad complex in the Nodal signaling pathway (Pei et al., 2007), were delayed in both epiboly and convergence movements, and ingression was severely impaired. Microarray analysis revealed that several EVL-specific intermediate filament genes were downregulated in foxh 1 morphants, suggesting they had defects in $E V L$ differentiation. Combined morpholino knockdown of these five intermediate filament genes phenocopied foxh1 morphants. Disruption of the Interferon Regulatory Factor (IRF) family transcription factor IRF6 also impairs EVL cell fate specification and epiboly, further supporting that proper EVL differentiation is essential for normal epiboly progression (Sabel et al., 2009).

Enhanced Nodal signaling, via knockdown of the Nodal antagonists lefty1 and lefty2, also delayed epiboly of deep cells (Feldman et al., 2002). Opposite to the phenotypes observed in foxh1 morphants and Nodal mutants, lefty $1 / 2$ double morphants had an expansion of hypoblast cell fates at the expense of epiblast fates and experienced an increase in internalization movements. Delayed epiboly in lefty $1 / 2$ morphants might result from too much internalization; however, as too much or too little internalization can be associated with epiboly delay, the morphant phenotype is more likely to be due to defects in cell fate specification.

\section{FGF signaling pathway}

In addition to Nodal pathway, the FGF signaling pathway plays a prominent role during early development, particularly in the specification and migration of mesoderm (reviewed in Heisenberg and Solnica-Krezel, 2008). Recent findings suggest a role for the FGF signaling pathway in epiboly initiation. Disruption of FGF signaling with high doses of the FGF receptor inhibitor SU5402 prevented epiboly initiation (Krens et al., 2008). Paradoxically, inhibition of other components of the FGF pathway, Xenopus FGFR1 (a dominant-negative FGF receptor) or $\mathrm{H}-\mathrm{Ras}$, had no effect on epiboly (Krens et al., 2008) and simultaneous morpholino knockdown of fgf8, fgf $17 \mathrm{~b}$ and fgf24 also did not inhibit epiboly initiation (Draper et al., 2003; Fürthauer et al., 2004; Poulain et al., 2006; Raible and Brand, 2001; Tsang et al., 2004). However, XenopusFGFR1 may not fully abrogate FGF signaling in zebrafish embryos. Furthermore, $40 \mathrm{fg} f$ genes have been isolated in zebrafish, some of which are expressed maternally (zfin.org), thus, it is probable that there is considerable redundancy in the system and that morpholino knockdowns are unlikely 
to lead to complete loss-of-function due to existing pools of maternal protein.

Further support for the role for FGF in epiboly, is the finding that morpholino knockdown of a downstream component of the FGF pathway, mitogen-activated protein kinase 1, mapk1 (formerly erk2), caused epiboly defects that were similar to SU5402 treatment (Krens et al., 2008). Injection of translation blocking mapk1-MO caused embryos to arrest at sphere stage or to exhibit severely delayed epiboly (Krens et al., 2008). Defects in mesoderm specification were also observed in morphant embryos and cells had an apparent reduction in protrusive activity, however, further work is needed to characterize these defects. As activated Mapk is localized to the EVL at oblong-sphere stages and to the EVL and marginal deep cells from dome stage onward, it would be interesting to determine whether the epiboly defect is autonomous to these cells.

Zebrafish angiomotin-like 2 (amot/2), a member of the Motin family of membrane associated scaffold proteins, appears to be another component of an FGF-regulated epiboly pathway (Huang et al., 2007). fgf8mRNA injection induced ectopic amot/2expression while treatment of embryos with SU5402 led to loss of amot/2 expression in ventral-lateral but not dorsal domains, suggesting that amot/2expression is partially regulated by FGF. Translation blocking amot/2-MO produced dose-dependent epiboly delay of the EVL, deep cells and YSL and, at high doses, doming was less pronounced than in control embryos. Morphants also had defects in convergent extension and were dorsalized.

The function of angiomotin-like genes in mammalian development is not known. However, inactivation of the founding member of the Motin family, Angiomotin, in mice leads to lethal defects in visceral endoderm migration (Shimono and Behringer, 2003) and Angiomotin has also been implicated in the maintenance of tight junctions between endothelial cells (Bratt et al., 2005). To determine the role of Amotl2 in cell migration in zebrafish, small clones of amot/2morphant cells were generated. Morphant cells failed to migrate normally and instead, cells frequently clustered on the surface of the yolk and displayed reduced protrusive activity relative to wild type cells (Huang et al., 2007). Both of these analyses were conducted after epiboly initiation was complete, thus, it is unclear whether earlier defects in doming can be attributed to perturbations in migratory behaviour. Interestingly, cell culture experiments showed that Amotl facilitates the localization of $\mathrm{c}$-Src to focal adhesions, suggesting a potential link between FGF signaling and the Src family of kinases in epiboly control (Huang et al., 2007) (see below).

\section{Src family protein kinases}

Members of the Src-family of protein tyrosine kinases, have been linked to epiboly initiation (Sharma et al., 2005; Tsai et al., 2005). Treatment of fertilized eggs with the synthetic Src-family kinase inhibitor PP2 had no affect on early cleavages, but epiboly and gastrulation failed to occur (Tsai et al., 2005). Specific knockdown of Fyn or Yes kinase, by dominant negative constructs and translation blocking morpholinos respectively, also led to epiboly arrest (Sharma et al., 2005; Tsai et al., 2005), while yesmorphants also displayed significant patterning and cell cycle defects (Tsai et al., 2005). Blocking Fyn kinase function had little effect on patterning but was sufficient to disrupt calcium transients that normally occur at the blastoderm margin during epiboly
(Sharma et al., 2005). It remains unclear whether the epiboly arrest is the primary result of Fyn or Yes kinase knockdown, as Jopling and den Hertog (2005) found that injection of low doses of either fynor yes-MOs had no effect on development, while coinjection of fyn- and yes-MOs caused defects in convergent extension but not epiboly. They also demonstrated that src-MO had no effect when co-injected with either yes- or fyn-MOs. Thus, it remains to be determined whether Fyn and Yes kinase are directly involved in epiboly control.

\section{Transcription factors}

The maternal transcription factors Pou Domain, class 5, transcription factor 1 (Pou5f1, also known as Oct4) and Eomesodermin A (Eomesa) are involved in epiboly initiation. In the zebrafish maternal-zygotic spiel ohne grenzen (MZspg) mutant, which carries a mutation in the pou5f1 gene, doming was delayed (Lachnit et al., 2008; Lunde et al., 2004; Reim et al., 2004). Epiboly of the deep cells, EVL and YSL were all delayed and mutant embryos were dorsalized and lacked endoderm (Lunde et al., 2004; Reim et al., 2004). Mspg mutant embryos displayed a similar but less severe epiboly delay, whereas Zspg mutant embryos appeared to go through epiboly at the normal rate, suggesting it is primarily maternal Pou5f1 that is required during epiboly initiation. Pou5f1 is a stem cell factor in mammals; however, the defect in epiboly initiation in MZspg embryos was not due to reduced cell number (Lachnit et al., 2008).

Microtubule organization in the yolk cell was normal during cleavage and blastula stages (Lachnit et al., 2008). However, by sphere stage, vesicular structures surrounded by microtubules, proposed to represent delayed cargo vesicles, were detected in the YCL of MZspg embryos. These results suggested that the doming delay could be primarily attributed to yolk cell microtubule defects, providing additional support for the importance of yolk cell microtubules for epiboly initiation. pou $5 f 1$ is expressed ubiquitously during cleavage and blastula stages but becomes restricted to the epiblast during gastrulation, suggesting it likely acts non-autonomously to affect the yolk cell. Transplantation studies indicated that the deep cell defects were also non-cell autonomous. However, in vitrocell sorting assays suggested that Pou5f1 deficient cells had different adhesion properties than wild type cells and, therefore, Pou5f1 may also have autonomous functions in deep cells (Lachnit et al., 2008).

Pou5f1 also has a role in epiboly progression. Starting at $50 \%$ epiboly, marginal EVL cells in MZspg mutant embryos failed to elongate and remained rounded, while the basal lamellipodia of EVL cells were greatly increased in mutant embryos at $75 \%$ and 90\% epiboly (Lachnit et al., 2008). YCL microtubules became severely disrupted at $50 \%$ epiboly, with large regions of the cortex becoming devoid of microtubules, while other regions contained broader microtubule bundles extending to the vegetal pole. Actin organization was similarly disrupted. Interesting, these defects were reminiscent of taxol treated embryos and embryos overexpressing gna13a (discussed below). Western blot analysis revealed no difference in $\beta$-tubulin levels in MZspg embryos, suggesting that Pou5f1 regulates the expression of factors involved in regulating microtubule organization during both phases of epiboly (Lachnit et al., 2008).

The maternal T-box gene Eomesodermin A (Eomesa) is critical for radial intercalation and subsequent thinning of the epiblast 
during epiboly (Bruce et al., 2005). Localized over-expression of a dominant-negative eomesa construct was sufficient to cell autonomously block the initiation of radial intercalation at the onset of epiboly. An important direction for future work will be to identify the transcriptional targets of Pou5f1 and Eomesa. An intriguing possibility is that these two transcription factors act together in epiboly initiation, as it has already been suggested that they act in parallel to affect endoderm specification (Bjornson et al., 2005). Our preliminary analysis of maternal and zygotic eomesa mutant embryos suggests that it is primarily maternal Eomesa that is involved in the doming process (unpublished data).

The zygotically expressed mix-type homeobox gene 2(mxtx2), identified as acting downstream of Eomesa, has a role in epiboly progression (Bruce et al., 2005). Embryos injected with mxtx2$\mathrm{MO}$ at the one-cell stage or into the YSL shortly after its formation, initiated epiboly properly but experienced epiboly arrest and subsequent yolk cell lysis during epiboly progression. Recent work on mxtx2from Wilkins et al. (2008) demonstrated that Mxtx2 functions in the YSL to organize the internal YSN and E-YSL actin ring. Subtle defects in microtubule organization were also noted. Taken together, this work suggests that Mxtx2 regulates genes involved in the formation and function of the yolk cell microtubule and actin networks.

\section{A sticky situation - the role of cell adhesion proteins}

The most thoroughly studied cell adhesion molecule implicated in epiboly is E-cadherin (epithelial cadherin 1, Cdh1). Cdh1 protein and transcript are maternally deposited (Babb et al., 2001; Babb and Marrs, 2004; Kane et al., 2005). Initially uniform transcript levels begin to drop revealing a mild gradient by $30 \%$ epiboly, with higher levels apparent in more superficial cells and lower levels in deeper cells (Kane et al., 2005). colh1 is also strongly expressed in the EVL, consistent with EM studies showing that junctional complexes resembling adherens junctions are present in the EVL (Kane et al., 2005; Montero et al., 2005). During epiboly, Cdh1 protein is detected in all cells at cellular interfaces, in cytoplasmic vesicles and near the vegetal most YSN (Babb and Marrs, 2004).

Injection of translation blocking cdh $1 \mathrm{MO}$ produced a hypomorphic phenotype characterized by irregular cleavages, failure of the blastoderm to compact and occasional shedding of cells from the blastoderm (Babb and Marrs, 2004). Surprisingly, morphant embryos recovered from these early defects and initiated epiboly; however, deep cell epiboly arrested by mid-gastrulation (Babb and Marrs, 2004). Similar defects were seen with several characterized colh1 mutant alleles (Kane et al., 2005; Shimizu et al., 2005). Zygotic-maternal dominant (ZMD) mutant embryos, in which both the maternal and zygotic genomes are heterozygous, are able to complete epiboly but do so at a slower rate (Kane et al., 2005). Embryos homozygous for a hypomorphic allele, $c d h^{r k 3}$, resembled the ZMD phenotype, whereas $\mathrm{MZ} c d h^{r k 3}$ mutant embryos experienced epiboly arrest, suggesting both maternal and zygotic Cdh1 are required for epiboly progression (Shimizu et al., 2005). The epiboly delay in cdh mutant embryos and morphants was confined to deep cells, thus providing the first indication that some aspects of deep cell epiboly are genetically separable from that of the EVL and YSL (Kane and Adams, 2002).

The deep cell epiboly phenotype associated with cdh1 mutant embryos and morphants is attributed to defects in radial intercalation in the epiblast, which had not previously been recognized as an important driving force in epiboly progression (Kane et al., 2005; Montero et al., 2005). This work revealed that the epiblast consists of two layers; cells of the exterior epiblast, adjacent to the EVL, have a flattened epithelial-like appearance while cells in the inner epiblast layer are less organized and often oriented with their long axis perpendicular to the epiblast surface. As the epiblast thins during epiboly progression, cells of the interior epiblast move radially into the exterior layer and flatten against the overlying EVL (Fig. 4, Kane et al., 2005). In colh1 mutant embryos, epiblast cells were rounder and the interior and exterior epiblast layers were less distinct. Although mutant cells moved radially into the exterior layer at a quicker rate than wild type cells, they retreated back to the interior at approximately the same rate. Individual colh1 mutant cells transplanted to wild type hosts also had defects in radial intercalation and contributed to the exterior epiblast less frequently than wild type cells, suggesting that the deep cell mutant phenotype is largely cell autonomous (Kane et al., 2005). Ultrastructural studies showed that adhesion between the EVL and deep cells is compromised in cdh1 morphant embryos (Shimizu et al., 2005).

From this work, the contribution of Cdh1 in the EVL to the

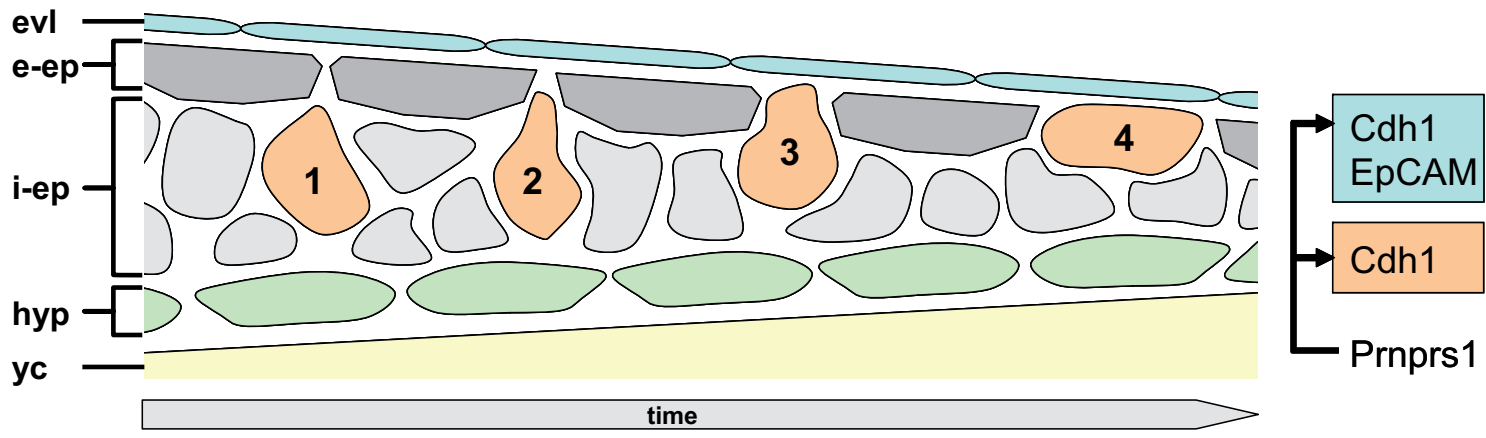

Fig. 4. Epiblast organization and radial intercalation during epiboly progression. The epiblast can be subdivided into an epithelial-like external layer (e-ep, dark grey) and an unorganized interior layer (i-ep, light grey). During epiboly progression, individual cells of the internal layer (1) move radially towards the EVL (2). Cells intercalate between cells in the external epiblast (3) and subsequently adhere to the overlying EVL and become incorporated into the external epiblast (4). Over time, this process contributes to the thinning and spreading of the deep cell layer. A representative intercalating epiblast cell is illustrated in peach, the EVL in blue, hypoblast (hyp) in green and yolk cell (yc) in yellow. The adhesion molecules involved in mediating this process are shown to the right (see text and Table 1 for details). Figure is adapted from Kane et al. (2005). 
epiboly defects observed in cdh 1 mutant embryos and morphants was unresolved. Recent work, however, has demonstrated that Cdh1 is required in the EVL for deep cell epiboly and, furthermore, that Cdh1 functions in a partially redundant manner with another transmembrane adhesion protein, Epithelial Cell Adhesion Molecule (EpCAM) (Slanchev et al., 2009).

epcam is expressed exclusively in the EVL during epiboly (Slanchev et al., 2009). Analysis of maternal-zygotic EpCAM (MZepcam) mutant embryos revealed that EVL cells had basally expanded tight junctions, while levels of membrane localized Cdh1 were reduced. Basal lamellipodia, evident on EVL cells during late epiboly (Lachnit et al., 2008), were also reduced in mutant cells. These findings suggest that EpCAM plays a role in limiting the basolateral extent of tight junctions and contributes to the localization of Cdh1. Injection of MZepcam embryos with a high dose of $c d h 1 \mathrm{MO}$ resulted in EVL disintegration and deep cell dissociation by early gastrulation. Mosaic analysis revealed that this phenotype was autonomous to the EVL and independent of Cdh1 expression in deep cells. Thus, EpCAM and Cdh1 act together in the EVL to maintain its integrity during epiboly.

In addition to defects in EVL cell polarity and integrity, MZepcam mutant embryos exhibited a mild delay in EVL and deep cell progression, causing the vegetal-most yolk to bulge from the blastopore at mid-gastrulation (Slanchev et al., 2009). To examine whether the two proteins also have a cooperative effect on epiboly progression, a suboptimal dose of Cdh1 MO was injected into MZepcam embryos, leading to an enhancement of the MZepcam phenotype (Slanchev et al., 2009). Similar to cdh1 mutant embryos, the partial knockdown of Cdh1 in a MZepcam background caused defects in deep cell radial intercalation. In transplantation experiments, wild type deep cells were unable to adhere and flatten against the basal EVL surface of MZepcam/ $c d h 1$ morphant hosts, whereas radial intercalation occurred normally in the reciprocal experiment. Taken together, this suggests that EpCAM and Cdh1 act synergistically in the EVL to promote adhesion of the deep cells to the basal surface of the EVL during epiboly.

A third cell adhesion molecule, Prion protein, also appears to be required for radial intercalation in the epiblast during epiboly progression. Prion protein is a membrane-tethered glycoprotein, an aberrant form of which is responsible for scrapie disease (Prusiner, 1991). While the pathological form of the protein has been extensively studied, little is known about its normal function (Aguzzi et al., 2008; Harris, 2003). Two Prion protein genes were identified in zebrafish, one of which, Prion protein related sequence 1 (Prnprs1), is expressed ubiquitously during gastrulation (Málaga-Trillo et al., 2009; Rivera-Milla et al., 2006). In cultured cells, GFP-tagged Prnprs1 localized to the cell membrane at points of contact with adjacent Prnprs1 positive cells, suggesting that it mediates homophilic cell adhesion. Embryos injected with translation blocking prnprs 1-MO exhibited gastrulation defects and most embryos arrested development at $9 \mathrm{hpf}$ (Málaga-Trillo et al., 2009). Epiboly of deep cells was clearly impaired, but no data were presented as to whether epiboly of the YSL and EVL were similarly affected.

As in Cdh1 mutants, intercalating epiblast cells failed to flatten against the EVL and frequently de-intercalated in prnprs 1 morphants (Málaga-Trillo et al., 2009). Membrane localization of Cdh1 and its intracellular adaptor $\beta$-Catenin was reduced in morphant deep cells. Instead, Cdh1 localized to Rab11 positive recycling endosomes, indicating a defect in Cdh1 trafficking. Embryo dissociation/re-aggregation assays demonstrated that Prnprs1 was required to localize $\operatorname{Cdh} 1$ and $\beta$-Catenin to the membrane at points of cell-cell contact. Furthermore, morphant cells formed smaller aggregates than wild type cells in re-aggregation assays and had abnormal rounded morphology when transplanted into wild type hosts. Together, this suggests that Prnprs 1 is required cell-autonomously to localize adhesion molecules to points of cell contact and mediate cell adhesion. A larger percentage of prnprs $1 /$ cdh 1 double morphants arrested at $6 \mathrm{hpf}$ than prnprs1 or colh1 single morphants, suggesting they act synergistically to regulate epiboly progression (Málaga-Trillo et al., 2009). Although not analyzed in detail, Prnprs1 was also needed for Fyn kinase to assemble at cell contacts, which is interesting in light of work suggesting that Fyn plays a role in epiboly (described above, Sharma et al., 2005).

Protocadherins are members of the cadherin superfamily that, unlike classical cadherins, do not interact with $\beta$-Catenin (Halbleib and Nelson, 2006). Two such cadherins, Protocadherin 18a (Pcdh18a) and Cadherin EGF LAG 7-pass G-type receptor (Celsr), have reported roles in epiboly progression. pcdh18a, first expressed in the late blastula, is expressed in the axial epiblast throughout gastrulation (Aamar and Dawid, 2008). Both overexpression and morpholino knockdown of pcdh18a caused delayed deep cell epiboly and convergent extension defects. The defects in morphogenesis correlated with changes in cell adhesiveness. In cell sorting assays, morphant cells aggregated and sorted from those over-expressing pcdh18a. Morphant blastoderms dissociated at a faster rate and to a greater extent than control blastoderms in a dissociation assay, suggesting Pcdh18a mediates cell adhesion. Other protocadherins have been shown to mediate cell adhesion indirectly through the regulation of classical cadherins, therefore, further study is required to determine whether Pcdh18a is playing a direct or indirect role in cell adhesion during epiboly (Chen and Gumbiner, 2006; Yasuda et al., 2007).

Celsr is the vertebrate homolog of the Drosophila atypical protocadherin flamingo, a core component of the planar cell polarity (PCP) pathway (Carreira-Barbosa et al., 2009). The zebrafish celsr genes (celsr1a, celsr1b, celsr2) are each expressed ubiquitously and act redundantly during gastrulation (Formstone and Mason, 2005). Although Celsr and other PCP proteins have been implicated in convergent extension, MZord (celsr2) mutant embryos exhibit few defects in early morphogenesis (Wada et al., 2006). By contrast, morpholino knockdown of both celsr1a and celsr1b in the MZord mutant background prevented blastopore closure in addition to resulting in defects in convergent extension (Carreira-Barbosa et al., 2009). The circumferential actin rings were organized properly and marginalmost EVL cells elongated normally, suggesting the epiboly defect was not the result of failed actomyosin contraction. EVL cells trailing the leading edge failed to elongate in $\mathrm{MZord} \mathrm{MO}$ injected embryos, suggesting marginal EVL-YSL interaction was normal while adhesion between EVL cells might be impaired. Deep cell epiboly was also arrested; however, this was likely a secondary consequence of the EVL defect since deep cells never surpass the EVL margin during epiboly (Carreira-Barbosa et al., 2009; Köppen et al., 2006). 
Work in other systems led to the idea that Celsr has two separable functions: a function in cell adhesion mediated by the extracellular cadherin repeats and a signaling functioning mediated by the 7-pass transmembrane domain and cytoplasmic tail (Shima et al., 2007; Shima et al., 2004). To determine which function is important for epiboly, constructs encoding a membrane tethered extracellular domain (Celsr- $\Delta \mathrm{C})$ and intracellular domain (Lyn-Celsr) were generated (Carreira-Barbosa et al., 2009). Injection of mRNA encoding Celsr- $\Delta \mathrm{C}$ into either wild type or MZordmutant embryos resulted in epiboly defects, whereas the Lyn-Celsr construct produced convergent extension defects but normal epiboly. Therefore, the cell adhesion function of Celsr is required for epiboly.

\section{G-protein coupled receptor signaling pathways}

Celsr acts independently of its 7-pass transmembrane G-type receptor domain to regulate epiboly; however, other components of GPCR signaling pathways have been implicated in epiboly progression. Prostaglandin $\mathrm{E}_{2}\left(\mathrm{PGE}_{2}\right)$, an oxygenated metabolite of the fatty acid arachidonic acid, binds to G-protein coupled EP receptors to regulate migration of cells in vitro (Negishi et al., 1995). Two factors required for $P \mathrm{PE}_{2}$ biosynthesis, Cyclooxygenase-1 (Cox-1) and microsomal Prostaglandin E synthase (Ptges), are ubiquitously expressed maternally and zygotically in zebrafish (Cha et al., 2006). MO knockdown of either enzyme resulted in a dose-dependent delay or complete epiboly arrest (Cha et al., 2006; Cha et al., 2005; Grosser et al., 2002). Importantly, exogenous $\mathrm{PGE}_{2}$ treatment was sufficient to rescue the cox-1 and ptges morphant phenotypes (Cha et al., 2006). Over-expression of ptges or cox-1, or providing excess $\mathrm{PGE}_{2}$, did not affect gastrulation, suggesting that $\mathrm{PGE}_{2}$ plays a permissive role in epiboly (Cha et al., 2006). Recent evidence shows that $\mathrm{PGE}_{2}$ signals through $\mathrm{G} \beta \gamma$ subunits to stabilize Snail1a, an inhibitor of $c d h 1$ expression, to regulate cell adhesion during gastrulation (Speirs et al., 2010).

In addition to delayed epiboly, ptges morphants also experienced defects in convergent extension and internalization (Speirs et al., 2010; Cha etal., 2006). Morpholino knockdown of a putative $\mathrm{PGE}_{2}$ receptor, Ptger4a, also impaired convergent extension and co-injection of sub-threshold doses of ptger4a and ptges MOs suggested that the two act in the same genetic pathway. Notably, however, ptger4a morphants did not have delayed epiboly, suggesting that a different receptor is involved in epiboly, or that maternal Ptger4a mediates the process. PGE ${ }_{2}$ stimulates cancer metastasis via activation of PI3K/Akt pathway (Buchanan et al., 2003; Sheng etal., 2001). This pathway appears to be conserved in zebrafish, as chemical inhibition of PI3K resulted in epiboly and convergent extension defects (Cha et al., 2006). Furthermore, ptgesmorphants experienced a significant decrease in active Akt, a target of PI3K phosphorylation.

Functional analysis of $\mathrm{G} \alpha$ subunits has provided more direct evidence that GPCR signaling plays an important role in epiboly progression. Members of the $\mathrm{G}_{12 / 13}$ class (gna12, gna13a, gna13b), first implicated in convergent extension movements, have recently been shown to be involved in epiboly (Lin et al., 2009; Lin et al., 2005). Combined morpholino knockdown of gna12 13al 13b, injection of mRNA encoding a dominant-negative Gna13a C-terminal peptide, or over-expression of gna13a resulted in a moderate delay in epiboly progression of the deep cell and EVL layers.

In vitro, members of the mammalian $\mathrm{G \alpha}_{12 / 13}$ class inhibit intercellular adhesion by blocking Cadherin from binding to $\beta$ Catenin (Kaplan et al., 2001; Meigs et al., 2001). As the $\mathrm{G}_{12 / 13}$ loss- and gain-of-function phenotype closely resembled that of cdh1 mutants, Lin et al. (2009) sought to determine whether the zebrafish $\mathrm{G} \alpha_{12 / 13}$ negatively regulates cell adhesion in a similar manner during epiboly. In transfected HEK 293 cells, Gna13a and $\beta$-Catenin competed to bind Cdh1 but surprisingly, the level and intracellular distribution of both Cdh1 and $\beta$-Catenin were normal in gna12 12al 13b triple morphants and embryos overexpressing gna13a (Lin et al., 2009). Although distribution of Cdh1 and $\beta$-Catenin were unaltered, genetic interaction experiments demonstrated that $\mathrm{G} \alpha_{12 / 13}$ negatively regulates Cdh1 function in some manner. Consistent with $\mathrm{G} \alpha_{12 / 13}$ having a negative effect on cell adhesion, small clones of cells injected with gna13a mRNA dispersed to a greater extent than control clones during late blastula-early gastrula stages. It is unclear, however, whether this is a defect in Cdh1-mediated radial intercalation or the result of some other aberrant cell movement.

Unlike $c d h 1$ mutant embryos, altering $\mathrm{G \alpha}_{12 / 13}$ function caused a delay in both deep cell and EVL epiboly, suggesting that $G \alpha_{12 /}$ ${ }_{13}$ has Cdh1-independent functions (Lin et al., 2009). Phalloidin staining revealed that marginal EVL cells failed to elongate along the animal-vegetal axis, suggesting a potential defect in marginal actomyosin constriction. Consistent with this prediction, the punctate actin in the E-YSL was disrupted in response to gna13aoverexpression. Over-expression of gna13a also had a unique effect on the YCL, which does not occur in cdh1 mutants. Reminiscent of embryos treated with taxol, embryos injected with gna13a mRNA had irregularities and distortions in the YCL, which correlated with abnormal bundling of cortical yolk cell actin (Lin et al., 2009).

$\mathrm{G}_{12 / 13}$ can act through a RhoGEF/Rho-dependent pathway to affect the actin cytoskeleton, cell shape and migration of cultured cells (Buhl et al., 1995; Gohla et al., 1998; Hart et al., 1998; Kozasa et al., 1998). In transfected HEK 293 cells, zebrafish Gna13a was found to interact with Arhgef11, a RhoGEF capable of inducing stress fiber formation (Lin et al., 2005; Panizzi et al., 2007). Although arhgef1 morpholino knockdown had no effect on epiboly, over-expression of arhgef1 phenocopied embryos overexpressing Gna13a (Lin et al., 2009). Expression of a dominantnegative version of Arhgef11 rescued the actin defects in the yolk, but failed to rescue the deep cell epiboly delay (Lin et al., 2009). Lin et al. (2009) proposed that $\mathrm{G \alpha}_{12 / 13}$ acts in the deep cells to negatively regulate Cdh1 function so that epiboly can proceed while in the yolk, $\mathrm{G \alpha}_{12 / 13}$ acts via RhoGEF-dependent mechanism to regulate the actin cytoskeleton.

\section{Unifying themes and open questions}

The most striking conclusion from recent work on zebrafish epiboly is that the simple model in which the EVL and deep cells are towed vegetally by the yolk cell is no longer sufficient. Below we attempt to synthesize recent progress, draw some conclusion about zebrafish epiboly and outline directions for future research.

\section{How are initiation and progression coordinated?}

Epiboly initiation and progression appear to involve both simi- 
lar and distinct cellular mechanisms. It is noteworthy that when epiboly initiation is completely blocked, epiboly progression does not proceed. Thus, initiation and progression are tightly coordinated, but whether this reflects similar underlying cellular and molecular mechanisms remains to be determined. It is still not known how epiboly is initiated, but deep cell motility coupled with yolk cell doming results in widespread deep cell radial intercalation, which thins the blastoderm and increases its surface area (Kane and Kimmel, 1993; Warga and Kimmel, 1990; Wilson et al., 1995). During the second phase, yolk microtubule and actin networks emerge as the major driving force behind epiboly progression (Cheng et al., 2004; Holloway et al., 2009; Köppen et al., 2006; Solnica-Krezel and Driever, 1994). The actin network in the E-YSL influences actin-based shape changes in the marginal EVL cells that are required for marginal constriction and subsequent blastopore closure (Köppen et al., 2006). Calcium waves, which travel around the blastoderm margin during epiboly progression, may trigger myosin-dependent contraction of the actin networks (Holloway et al., 2009; Köppen et al., 2006). Deep cell radial intercalation is also important for epiboly progression, it involves adhesion and flattening of deep cells against the inner surface of the EVL, and is mediated in large part by adhesion molecules expressed in the EVL (Kane et al., 2005; Málaga-Trillo etal., 2009; Shimizu etal., 2005; Slanchev etal., 2009). Additional experiments are needed to determine whether radial intercalation during initiation and progression occur through similar or distinct mechanisms.

Determining whether a given factor plays a role in initiation, progression or both is hampered by the fact that most factors linked to epiboly are maternally expressed. Complete removal of the maternal contribution can only be achieved by generating maternal mutants. As the current repertoire of mutant lines with epiboly defects is rather limited and targeted mutagenesis is still in its infancy for zebrafish, this is not an option for most genes (Doyon etal., 2008; Kane etal., 1996; Meng etal., 2008; Reim and Brand, 2006; Slanchev et al., 2009; Solnica-Krezel et al., 1996; Wagner et al., 2004). Even when maternal or maternal-zygotic mutants can be generated, they may have early defects that lead to lethality or severe abnormalities before epiboly starts. Because morpholino knockdown, which has no effects on extant protein, has been the most widely used approach to determine gene function in the zebrafish, the total number of genes implicated in epiboly is likely underestimated. Furthermore, the extent to which identified factors are involved in both phases of epiboly remains unclear. In light of these issues, it will take a considerable amount of future study to determine the underlying genetic mechanisms of epiboly and how the two phases may be linked.

\section{Do deep cells move actively or passive during epiboly?}

Radial intercalation during zebrafish doming has been equated to the process of radial interdigitation, one of the cellular mechanisms of epiboly described in Xenopus (Keller, 1980; Warga and Kimmel, 1990). In the frog, the surface area of the ectoderm expands by radial interdigitation of deep cells (Keller, 1980). Cells extend processes and move between each other, transforming the blastocoel roof from a multilayered structure to one that is two cells thick. The ectodermal sheet subsequently flattens to allow continued spreading during epiboly. The presence of cellular protrusions oriented in the direction of radial cell movements may indicate an active component to these cell movements. Alternatively, tension in the overlying superficial epithelium (analogous to the zebrafish EVL), generated at the blastopore margin, may result in passive cell rearrangement.

Although the two processes are routinely compared, it remains unclear how similar zebrafish radial intercalation is to radial interdigitation in Xenopus. This is because detailed data about cell behaviour, morphology and protrusive activity are scant for these early stages in both systems. In zebrafish, radial intercalation during both epiboly initiation and progression may result from the modulation of cell adhesions, which enables passive cell rearrangements to occur. However, more work is needed to determine whether active, directed cell movements play any role in epiboly.

\section{What role does cell-matrix adhesion play?}

While it has been demonstrated that cellular rearrangement during zebrafish epiboly requires the dynamic regulation of intercellular adhesion, it is unclear whether cell-matrix adhesions are regulated in a similar manner. Until recently, little was known about the assembly and organization of extracellular matrix (ECM) during epiboly stages. Fibronectin and laminin are first detected at $65 \%$ epiboly at the epiblast-hypoblast and blastoderm-yolk interfaces (Latimer and Jessen, 2010). Through the end of gastrulation, fibronectin and laminin organize into fibrils, forming matrices at tissue boundaries. Even less is known about the function of the ECM during gastrulation. The zebrafish fibronectin mutant, natter (nat), undergoes early morphogenesis normally; however, it was reported, with data not shown, that $\mathrm{MZnatter}$ mutants have defects in gastrulation movements (Trinh and Stainier, 2004). This preliminary finding has not been followed up. As fibronectin fibrillogenesis has been shown to be required for radial intercalation movements during epiboly in Xenopus (Cousin et al., 2008; Marsden and DeSimone, 2001), cell-matrix interactions deserve further investigation in the zebrafish.

\section{A starring role for the enveloping layer (EVL)?}

During epiboly, interactions occur between cells within the EVL sheet, between marginal EVL cells and the underlying E-YSL, and between EVL and deep cells. EVL-EVL interactions are required to establish a permeability barrier against the environment and proper adhesion within the EVL sheet is also necessary so that it can withstand considerable stretching, allowing it to maintain its integrity as it proceeds to the vegetal pole.

Based on work in Fundulus, the traditional view of the marginal EVL-YSL relationship is that the EVL is pulled vegetally by its tight junction attachments to the YSL and, thus, is unlikely to actively migrate during epiboly (Betchaku and Trinkaus, 1978). Recently, we have shown that knockdown of the tight junction component Claudin E (Cldn E) disrupts the margin EVL-YSL connection and leads to epiboly delay, suggesting that a tight junction EVL-YSL connection is important during zebrafish epiboly as well (Siddiqui et al., 2010). Unlike Fundulus, filopodia are evident on marginal EVL cells during early epiboly in the zebrafish (Betchaku and Trinkaus, 1978; Köppen et al., 2006; Zalik et al., 1999). Filopodia are no longer detected after $50 \%$ epiboly, which correlates with the EVL margin becoming much smoother and with the assembly of the cortical actin ring implicated in marginal constriction (Cheng 
et al., 2004; Köppen et al., 2006). One argument made against active EVL migration in Fundulus, was that EVL-YSL tight junctions would have to be constantly broken and remade, for which there was no evidence (Betchaku and Trinkaus, 1978). However, in both Fundulus and zebrafish, cell rearrangement within the EVL results in a reduction in the number of cells at the EVL margin as the blastopore closes (Betchaku and Trinkaus, 1978; Köppen et al., 2006). Thus, attachments between the EVL and YSL can be broken and perhaps reformed as the cell rearrangements take place. Another issue is the timing of initial tight junction formation between the EVL and YSL in zebrafish. If EVL-YSL tight junctions are not present until after $50 \%$ epiboly, it would support the hypothesis that marginal EVL cells initially actively migrate until a transition to YSL pulling occurs.

Recent work has highlighted the importance of EVL-deep cell interactions for epiboly, particularly for normal deep cell epiboly. These findings suggest that the basal EVL surface acts as a substrate for outer epiblast cells during epiboly and, likewise, the EVL may gain traction by interacting with underlying deep cells. This also raises the possibility of signaling between the two layers. To effectively test this, new methods to manipulate gene expression specifically in the EVL, without affecting deep cells, will be necessary.

\section{The calcium connection}

Dynamic changes in calcium levels that occur during early development may play a role in regulating both the initiation and progression phases of zebrafish epiboly. First, short-range calcium waves in superficial and marginal blastomeres precede the formation of EVL and YSL during the blastula period and could play a role in their formation (Webb and Miller, 2006). If calcium waves are involved in establishing and maintaining these tissues, blastula period calcium waves might also be a prerequisite for epiboly to proceed normally. As previously discussed, embryos injected with a dominant-negative Fyn kinase construct failed to initiate epiboly and, interestingly, had reduced marginal calcium flux just prior to when control embryos domed (Sharma et al., 2005).

Calcium waves have a clearer role in epiboly progression (Cheng et al., 2004; Sharma et al., 2005). Long-range, panembryonic intercellular calcium waves emanate from the dorsal side of the embryo and travel around the margin during gastrulation (reviewed in Webb and Miller, 2006). These calcium waves do not begin until the blastoderm passes the equator, correlating well with the onset of contraction of the marginal actin ring and suggesting that calcium mediates this contraction (Webb and Miller, 2006). Consistent with this prediction, precocious marginal constriction in $b b p$ mutants correlated with increased amplitude and frequency of marginal calcium waves (Holloway et al., 2009). In addition, injection of calcium chelators into the YSL after epiboly initiation is sufficient to arrest epiboly progression (Cheng etal., 2004; Sharma etal., 2005). Waves are thought to propagate via diffusion of IP3 or calcium ions through gap junctions (Slusarski and Pelegri, 2007). Intriguingly, gap junction permeability has been reported to increase in marginal cells during gastrulation (Bozhkova and Voronov, 1997). Gap junction passage of calcium to the YSL might also occur, leading to activation of Myosin 2mediated actin contraction.

\section{Conclusion}

Recent work on zebrafish epiboly has revealed the process to be considerably more complex than previously appreciated. Rather than the blastoderm playing a passive role in epiboly, it appears that all layers of the early embryo participate in the process and interact in intricate ways. How epiboly is coordinated with the other movements of gastrulation is an intriguing open question. There is still much to learn, and we eagerly await the new insights likely to emerge from future studies.

\section{Acknowledgements}

We thank Rudi Winklbauer and Rachel Warga for comments on the manuscript and helpful discussions. AB is supported by NSERC and CFI.

\section{References}

AAMAR, E. and DAWID, I. B. (2008). Protocadherin-18a has a role in cell adhesion, behavior and migration in zebrafish development. Dev Bio/318: 335-346.

AGUZZI, A., BAUMANN, F. and BREMER, J. (2008). The prion's elusive reason for being. Annu Rev Neurosci31: 439-477.

BABB, S. G., BARNETT, J., DOEDENS, A. L., COBB, N., LIU, Q., SORKIN, B. C., YELICK, P. C., RAYMOND, P. A. and MARRS, J. A. (2001). Zebrafish Ecadherin: expression during early embryogenesis and regulation during brain development. Dev Dyn 221: 231-237.

BABB, S. G. and MARRS, J. A. (2004). E-cadherin regulates cell movements and tissue formation in early zebrafish embryos. Dev Dyn 230: 263-277.

BETCHAKU, T. and TRINKAUS, J. P. (1978). Contact relations, surface activity and cortical microfilaments of marginal cells of the enveloping layer and of the yolk syncytial and yolk cytoplasmic layers of Fundulus before and during epiboly. $J$ Exp Zoo/206: 381-426.

BETCHAKU, T. and TRINKAUS, J. P. (1986). Programmed endocytosis during epiboly of Fundulus heteroclitus. Am Zoo/26: 193-199.

BJORNSON, C. R., GRIFFIN, K. J., FARR, G. H., 3RD, TERASHIMA, A., HIMEDA, C., KIKUCHI, Y. and KIMELMAN, D. (2005). Eomesodermin is a localized maternal determinant required for endoderm induction in zebrafish. Dev Cel/9: 523-533.

BOZHKOVA, V. and VORONOV, D. (1997). Spatial-temporal characteristics of intercellular junctions in early zebrafish and loach embryos before and during gastrulation. Dev Genes Evo/207: 115-126.

BRATT, A., BIROT, O., SINHA, I., VEITONMÄKI, N., AASE, K., ERNKVIST, M. and HOLMGREN, L. (2005). Angiomotin regulates endothelial cell-cell junctions and cell motility. J Biol Chem 280: 34859-34869.

BRUCE, A. E., HOWLEY, C., DIXON FOX, M. and HO, R. K. (2005). T-box gene eomesodermin and the homeobox-containing Mix/Bix gene $\mathrm{mtx} 2$ regulate epiboly movements in the zebrafish. Dev Dyn 233: 105-114.

BUCHANAN, F. G., WANG, D., BARGIACCHI, F. and DUBOIS, R. N. (2003). Prostaglandin E2 regulates cell migration via the intracellular activation of the epidermal growth factor receptor. J Biol Chem 278: 35451-35457.

BUHL, A. M., JOHNSON, N. L., DHANASEKARAN, N. and JOHNSON, G. L. (1995). Go12 and $\mathrm{G} \alpha 13$ stimulate Rho-dependent stress fiber formation and focal adhesion assembly. J Biol Chem 270: 24631-24634.

CARREIRA-BARBOSA, F., KAJITA, M., MOREL, V., WADA, H., OKAMOTO, H. MARTINEZ ARIAS, A., FUJITA, Y., WILSON, S. W. and TADA, M. (2009). Flamingo regulates epiboly and convergence/extension movements through cell cohesive and signalling functions during zebrafish gastrulation. Development 136: 383-392.

CARVALHO, L., STUHMER, J., BOIS, J. S., KALAIDZIDIS, Y., LECAUDEY, V. and HEISENBERG, C. P. (2009). Control of convergent yolk syncytial layer nuclear movement in zebrafish. Development 136: 1305-1315.

CHA, Y. I., KIM, S. H., SEPICH, D., BUCHANAN, F. G., SOLNICA-KREZEL, L. and DUBOIS, R. N. (2006). Cyclooxygenase-1-derived PGE2 promotes cell motility via the G-protein-coupled EP4 receptor during vertebrate gastrulation. Genes Dev20: 77-86. 
CHA, Y. I., KIM, S. H., SOLNICA-KREZEL, L. and DUBOIS, R. N. (2005). Cyclooxygenase-1 signaling is required for vascular tube formation during development. Dev Bio/282: 274-283.

CHEN, X. and GUMBINER, B. M. (2006). Paraxial protocadherin mediates cell sorting and tissue morphogenesis by regulating $\mathrm{C}$-cadherin adhesion activity. $\checkmark$ Cell Biol 174: 301-313.

CHENG, J. C., MILLER, A. L. and WEBB, S. E. (2004). Organization and function of microfilaments during late epiboly in zebrafish embryos. Dev Dyn231: 313323.

COUSIN, H., DESIMONE, D. W. and ALFANDARI, D. (2008). PACSIN2 regulates cell adhesion during gastrulation in Xenopus laevis. Dev Bio/391: 86-99.

DOSCH, R., WAGNER, D. S., MINTZER, K. A., RUNKE, G., WIEMELT, A. P. and MULLINS, M. C. (2004). Maternal control of vertebrate development before the midblastula transition: Mutants from the zebrafish I. Dev Ce//6: 771-780.

DOWNIE, J. R. and PEGRUM, S. M. (1971). Organization of the chick blastoderm edge. J Embryol Exp Morph 26: 623-635.

DOYON, Y., MCCAMMON, J. M., MILLER, J. C., FARAJI, F., NGO, C., KATIBAH, G. E., AMORA, R., HOCKING, T. D., ZHANG, L., REBAR, E. J. et al. (2008). Heritable targeted gene disruption in zebrafish using designed zinc-finger nucleases. Nat Biotechno/26: 702-708.

DRAPER, B. W., STOCK, D. W. and KIMMEL, C. B. (2003). Zebrafish fgf24 functions with fgf8 to promote posterior mesodermal development. Development 130: 4639-4654.

EBERT, A. M., MCANELLY, C. A., SRINIVASAN, A., LINKER, J. L., HORNE, W. A. and GARRITY, D. M. (2008). Ca2+ channel-independent requirement for MAGUK family CACNB4 genes in initiation of zebrafish epiboly. Proc Nat/Acad Sci USA 105: 198-203.

ESSNER, J. J., AMACK, J. D., NYHOLM, M. K., HARRIS, E. B. and YOST, H. J. (2005). Kupffer's vesicle is a ciliated organ of asymmetry in the zebrafish embryo that initiates left-right development of the brain, heart and gut. Deve/opment 132: 1247-1260.

FELDMAN, B., CONCHA, M. L., SAUDE, L., PARSONS, M. J., ADAMS, R. J., WILSON, S. W. and STEMPLE, D. L. (2002). Lefty antagonism of Squint is essential for normal gastrulation. Curr Bio/12: 2129-2135.

FORMSTONE, C. J. and MASON, I. (2005). Combinatorial activity of Flamingo proteins directs convergence and extension within the early zebrafish embryo via the planar cell polarity pathway. Dev Bio/282: 320-335.

FÜRTHAUER, M., VAN CELST, J., THISSE, C. and THISSE, B. (2004). Fgf signalling controls the dorsoventral patterning of the zebrafish embryo. Development 131: 2853-2864.

GILBERT, S. F. (2003). Developmental Biology. Sinauer Associates, Inc., Sunderland.

GOHLA, A., HARHAMMER, R. and SCHULTZ, G. (1998). The G-protein Go13 but not $\mathrm{G} \alpha 12$ mediates signaling from lysophosphatidic acid receptor via epidermal growth factor receptor to Rho. J Biol Chem 273: 4653-4659.

GOODE, B. L. and ECK, M. J. (2007). Mechanism and function of formins in the control of actin assembly. Annu Rev Biochem 76: 593-627.

GROSSER, T., YUSUFF, S., CHESKIS, E., PACK, M. A. and FITZGERALD, G. A (2002). Developmental expression of functional cyclooxygenases in zebrafish. Proc Natl Acad Sci USA 99: 8418-8423.

HALBLEIB, J. M. and NELSON, W. J. (2006). Cadherins in development: cell adhesion, sorting, and tissue morphogenesis. Genes Dev20: 3199-3214.

HARRIS, D. A. (2003). Trafficking, turnover and membrane topology of PrP. BrMed Bul/66: 71-85.

HART, M. J., JIANG, X., KOZASA, T., ROSCOE, W., SINGER, W. D., GILMAN, A. G., STERNWEIS, P. C. and BOLLAG, G. (1998). Direct stimulation of the guanine nucleotide exchange activity of p115 RhoGEF by $\mathrm{G} \alpha 13$. Science 280: 2112-2114.

HEISENBERG, C. P. and SOLNICA-KREZEL, L. (2008). Back and forth between cell fate specification and movement during vertebrate gastrulation. Curr Opin Genet Dev 18: 311-316.

HOLLOWAY, B. A., GOMEZ DE LA TORRE CANNY, S., YE, Y., SLUSARSKI, D. C., FREISINGER, C. M., DOSCH, R., CHOU, M. M., WAGNER, D. S. and MULLINS, M. C. (2009). A novel role for MAPKAPK2 in morphogenesis during zebrafish development. PLOS Genet5: e1000413.
HSU, H. J., HSIAO, P., KUO, M. W. and CHUNG, B. C. (2002). Expression of zebrafish cyp11a1 as a maternal transcript and in yolk syncytial layer. Gene Expr Patterns 2: 219-222.

HSU, H. J., LIANG, M. R., CHEN, C. T. and CHUNG, B. C. (2006). Pregnenolone stabilizes microtubules and promotes zebrafish embryonic cell movement. Nature 439: 480-483.

HUANG, H., LU, F. I., JIA, S., MENG, S., CAO, Y., WANG, Y., MA, W., YIN, K., WEN, Z., PENG, J. et al. (2007). Amotl2 is essential for cell movements in zebrafish embryo and regulates c-Src translocation. Development 134: 979-988.

JOPLING, C. and DEN HERTOG, J. (2005). Fyn/Yes and non-canonical Wnt signalling converge on RhoA in vertebrate gastrulation cell movements. $E M B O$ Rep 6: 426-431.

KANE, D. and ADAMS, R. (2002). Life at the edge: epiboly and involution in the zebrafish. Results Prob/ Cell Differ 40: 117-135

KANE, D. A., HAMMERSCHMIDT, M., MULLINS, M. C., MAISCHEIN, H. M., BRAND, M., VAN EEDEN, F. J., FURUTANI-SEIKI, M., GRANATO, M. HAFFTER, P., HEISENBERG, C. P. et al. (1996). The zebrafish epiboly mutants. Development 123: 47-55.

KANE, D. A. and KIMMEL, C. B. (1993). The zebrafish midblastula transition. Development 119: 447-456.

KANE, D. A., MCFARLAND, K. N. and WARGA, R. M. (2005). Mutations in half baked/E-cadherin block cell behaviors that are necessary for teleost epiboly. Development 132: 1105-1116.

KANE, D. A., WARGA, R. M. and KIMMEL, C. B. (1992). Mitotic domains in the early embryo of the zebrafish. Nature 360: 735-737.

KAPLAN, D. D., MEIGS, T. E. and CASEY, P. J. (2001). Distinct regions of the cadherin cytoplasmic domain are essential for functional interaction with $\mathrm{G} \alpha 12$ and $\beta$-catenin. J Biol Chem 276: 44037-44043.

KELLER, R. E. (1980). The cellular basis of epiboly: an SEM study of deep-cell rearrangement during gastrulation in Xenopus laevis. J Embryol Exp Morphol 60: $210-234$

KIMMEL, C. B., BALLARD, W. W., KIMMEL, S. R., ULLMANN, B. and SCHILLING T. F. (1995). Stages of embryonic development of the zebrafish. Dev Dyn 203 253-310.

KIMMEL, C. B. and LAW, R. D. (1985). Cell lineage of zebrafish blastomeres. II. Formation of the yolk syncytial layer. Dev Bio/108: 86-93.

KIMMEL, C. B., WARGA, R. M. and SCHILLING, T. F. (1990). Origin and organization of the zebrafish fate map. Development 108: 581-594.

KÖPPEN, M., FERNÁNDEZ, B. G., CARVALHO, L., JACINTO, A. and HEISENBERG, C. P. (2006). Coordinated cell-shape changes control epithelial movement in zebrafish and Drosophila. Development 133: 2671-2681.

KOZASA, T., JIANG, X., HART, M. J., STERNWEIS, P. M., SINGER, W. D., GILMAN, A. G., BOLLAG, G. and STERNWEIS, P. C. (1998). p115 RhoGEF, a GTPase activating protein for $\mathrm{G} \alpha 12$ and $\mathrm{G} \alpha 13$. Science 280: 2109-2111.

KRAMER-ZUCKER, A. G., OLALE, F., HAYCRAFT, C. J., YODER, B. K., SCHIER A. F. and DRUMMOND, I. A. (2005). Cilia-driven fluid flow in the zebrafish pronephros, brain and Kupffer's vesicle is required for normal organogenesis. Development 132: 1907-1921.

KRENS, S. F., HE, S., LAMERS, G. E., MEIJER, A. H., BAKKERS, J., SCHMIDT, T., SPAINK, H. P. and SNAAR-JAGALSKA, B. E. (2008). Distinct functions for ERK1 and ERK2 in cell migration processes during zebrafish gastrulation. Dev Bio/319: 370-383.

LACHNIT, M., KUR, E. and DRIEVER, W. (2008). Alterations of the cytoskeleton in all three embryonic lineages contribute to the epiboly defect of Pou5f1/Oct4 deficient MZspg zebrafish embryos. Dev Bio/315: 1-17.

LADWEIN, M. and ROTTNER, K. (2008). On the Rho'd: the regulation of membrane protrusions by Rho-GTPases. FEBS Lett582: 2066-2074

LAI, S. L., CHAN, T. H., LIN, M. J., HUANG, W. P., LOU, S. W. and LEE, S. J. (2008) Diaphanous-related formin 2 and profilin I are required for gastrulation cell movements. PLoS One 3: e3439.

LATIMER, A.J. and JESSEN, J. (2010). Extracellular matrix assembly and organization during zebrafish gastrulation. Matrix Biol 29: 89-96. (DOI:10.1016/ j.matbio.2009.10.002)

LESKOW, F. C., HOLLOWAY, B. A., WANG, H., MULLINS, M. C. and KAZANIETZ, M. G. (2006). The zebrafish homologue of mammalian chimerin Rac-GAPs is 
implicated in epiboly progression during development. Proc Nat/ $\mathrm{Acad} \mathrm{SCl}$ USA 103: 5373-5378.

LIN, F., CHEN, S., SEPICH, D. S., PANIZZI, J. R., CLENDENON, S. G., MARRS, J. A., HAMM, H. E. and SOLNICA-KREZEL, L. (2009). Galpha12/13 regulate epiboly by inhibiting E-cadherin activity and modulating the actin cytoskeleton. J Cel/ Bio/ 184: 909-921.

LIN, F., SEPICH, D. S., CHEN, S., TOPCZEWSKI, J., YIN, C., SOLNICAKREZEL, L. and HAMM, H. (2005). Essential roles of G\{alpha\}12/13 signaling in distinct cell behaviors driving zebrafish convergence and extension gastrulation movements. J Cel/ Bio/ 169: 777-787.

LUNDE, K., BELTING, H. G. and DRIEVER, W. (2004). Zebrafish pou5f1/pou2, homolog of mammalian Oct4, functions in the endoderm specification cascade. Curr Bio/ 14: 48-55.

MÁLAGA-TRILLO, E., SOLIS, G. P., SCHROCK, Y., GEISS, C., LUNCZ, L., THOMANETZ, V. and STUERMER, C. A. (2009). Regulation of embryonic cell adhesion by the prion protein. PLOS Bio/7: e55.

MARSDEN, M. and DESIMONE, D. W. (2001). Regulation of cell polarity, radial intercalation and epiboly in Xenopus: novel roles for integrin and fibronectin. Development 128: 3635-3647.

MEIGS, T. E., FIELDS, T. A., MCKEE, D. D. and CASEY, P. J. (2001). Interaction of $\mathrm{G} \alpha 12$ and $\mathrm{G} \alpha 13$ with the cytoplasmic domain of cadherin provides a mechanism for beta -catenin release. Proc Nat/ Acad Sci USA 98: 519-524.

MENG, X., NOYES, M. B., ZHU, L. J., LAWSON, N. D. and WOLFE, S. A. (2008). Targeted gene inactivation in zebrafish using engineered zinc-finger nucleases. Nat Biotechno/26: 695-701.

MONTERO, J. A., CARVALHO, L., WILSCH-BRAUNINGER, M., KILIAN, B., MUSTAFA, C. and HEISENBERG, C. P. (2005). Shield formation at the onset of zebrafish gastrulation. Development 132: 1187-1198.

NEGISHI, M., SUGIMOTO, Y. and ICHIKAWA, A. (1995). Molecular mechanisms of diverse actions of prostanoid receptors. Biochim Biophys Acta 1259: 109119.

OTEÍZA, P., KÖPPEN, M., CONCHA, M. L. and HEISENBERG, C. P. (2008). Origin and shaping of the laterality organ in zebrafish. Development 135 : 2807-2813.

PANIZZI, J. R., JESSEN, J. R., DRUMMOND, I. A. and SOLNICA-KREZEL, L. (2007). New functions for a vertebrate Rho guanine nucleotide exchange factor in ciliated epithelia. Development 134: 921-931.

PEI, W., NOUSHMEHR, H., COSTA, J., OUSPENSKAIA, M. V., ELKAHLOUN, A. G. and FELDMAN, B. (2007). An early requirement for maternal FoxH1 during zebrafish gastrulation. Dev Bio/310: 10-22.

POULAIN, M., FÜRTHAUER, M., THISSE, B., THISSE, C. and LEPAGE, T. (2006). Zebrafish endoderm formation is regulated by combinatorial Nodal, FGF and BMP signalling. Development 133: 2189-2200.

PRUSINER, S. B. (1991). Molecular biology of prion diseases. Science 252: 1515-1522.

RAIBLE, F. and BRAND, M. (2001). Tight transcriptional control of the ETS domain factors Erm and Pea3 by Fgf signaling during early zebrafish development. Mech Dev 107: 105-117.

REIM, G. and BRAND, M. (2006). Maternal control of vertebrate dorsoventral axis formation and epiboly by the POU domain protein Spg/Pou2/Oct4. Development 133: 2757-2770.

REIM, G., MIZOGUCHI, T., STAINIER, D. Y., KIKUCHI, Y. and BRAND, M. (2004). The POU domain protein spg (pou2/Oct4) is essential for endoderm formation in cooperation with the HMG domain protein casanova. Dev Cel/6: 91-101.

RIVERA-MILLA, E., OIDTMANN, B., PANAGIOTIDIS, C. H., BAIER, M., SKLAVIADIS, T., HOFFMANN, R., ZHOU, Y., SOLIS, G. P., STUERMER, C. A. and MALAGA-TRILLO, E. (2006). Disparate evolution of prion protein domains and the distinct origin of Doppel- and prion-related loci revealed by fish-to-mammal comparisons. FASEB J20: 317-319.

SABEL, J. L., D'ALENCON, C., O'BRIEN, E. K., VAN OTTERLOO, E., LUTZ, K., CUYKENDALL, T. N., SCHUTTE, B. C., HOUSTON, D. W. and CORNELL, R. A. (2009). Maternal Interferon Regulatory Factor 6 is required for the differentiation of primary superficial epithelia in Danio and Xenopus embryos. Dev Bio/325: 249-262.

SHARMA, D., HOLETS, L., ZHANG, X. and KINSEY, W. H. (2005). Role of Fyn kinase in signaling associated with epiboly during zebrafish development. Dev Bio/285: 462-476.

SHENG, H., SHAO, J., WASHINGTON, M. K. and DUBOIS, R. N. (2001). Prostaglandin E2 increases growth and motility of colorectal carcinoma cells. $J$ Biol Chem 276: 18075-18081.

SHIMA, Y., KAWAGUCHI, S. Y., KOSAKA, K., NAKAYAMA, M., HOSHINO, M., NABESHIMA, Y., HIRANO, T. and UEMURA, T. (2007). Opposing roles in neurite growth control by two seven-pass transmembrane cadherins. Nat Neurosci 10: 963-969.

SHIMA, Y., KENGAKU, M., HIRANO, T., TAKEICHI, M. and UEMURA, T. (2004). Regulation of dendritic maintenance and growth by a mammalian 7-pass transmembrane cadherin. Dev Cel/7: 205-216.

SHIMIZU, T., YABE, T., MURAOKA, O., YONEMURA, S., ARAMAKI, S., HATTA K., BAE, Y. K., NOJIMA, H. and HIBI, M. (2005). E-cadherin is required for gastrulation cell movements in zebrafish. Mech Dev 122: 747-763.

SHIMONO, A. and BEHRINGER, R. R. (2003). Angiomotin regulates visceral endoderm movements during mouse embryogenesis. Curr Bio/13: 613-617.

SIDDIQUI, M., SHEIKH, H., TRAN, C. and BRUCE, A. E. E. (2010). The tight junction protein Claudin $\mathrm{E}$ is required for zebrafish epiboly. Dev Dyn 239: 715-722.

SLANCHEV, K., CARNEY, T. J., STEMMLER, M. P., KOSCHORZ, B., AMSTERDAM, A., SCHWARZ, H. and HAMMERSCHMIDT, M. (2009). The epithelial cell adhesion molecule EpCAM is required for epithelial morphogenesis and integrity during zebrafish epiboly and skin development. PLOS Genet 5: e1000563.

SLUSARSKI, D. C. and PELEGRI, F. (2007). Calcium signaling in vertebrate embryonic patterning and morphogenesis. Dev Bio/307: 1-13.

SOLNICA-KREZEL, L. (2006). Gastrulation in zebrafish - all just about adhesion? Curr Opin Genet Dev 16: 433-441.

SOLNICA-KREZEL, L. and DRIEVER, W. (1994). Microtubule arrays of the zebrafish yolk cell: organization and function during epiboly. Development 120: 2443-2455.

SOLNICA-KREZEL, L., STEMPLE, D. L., MOUNTCASTLE-SHAH, E., RANGINI, Z., NEUHAUSS, S. C., MALICKI, J., SCHIER, A. F., STAINIER, D. Y., ZWARTKRUIS, F., ABDELILAH, S. et al. (1996). Mutations affecting cell fates and cellular rearrangements during gastrulation in zebrafish. Development 123: $67-80$

SPEIRS C. K., JERNIGAN, K. K., KIM, S.-H., CHA, Y. I., LIN, F., SEPICH, D. S., DUBOIS, R. N., LEE, E. and SOLNICA-KREZEL, L. (2010). Prostaglandin G signaling stimulates gastrulation movements by limiting cell adhesion through Snai1a stabilization. Development 137: 1327-1337.

STRÄHLE, U. and JESUTHASAN, S. (1993). Ultraviolet irradiation impairs epiboly in zebrafish embryos: evidence for a microtubule-dependent mechanism of epiboly. Development 119: 909-919.

TRINH, L. A. and STAINIER, D. Y. (2004). Fibronectin regulates epithelia organization during myocardial migration in zebrafish. Dev Ce//6: 371-382.

TRINKAUS, J. P. (1951). A study of mechanisms of epiboly in the egg of Fundulus heteroclitus. J Exp Zool 118: 269-320.

TRINKAUS, J. P. (1984). Mechanism of Fundulus epiboly-a current view. Am Zoo/24: 673-688.

TSAI, W. B., ZHANG, X., SHARMA, D., WU, W. and KINSEY, W. H. (2005). Role of Yes kinase during early zebrafish development. Dev Bio/277: 129-141.

TSANG, M., MAEGAWA, S., KIANG, A., HABAS, R., WEINBERG, E. and DAWID, I. B. (2004). A role for MKP3 in axial patterning of the zebrafish embryo. Development 131: 2769-2779.

WADA, H., TANAKA, H., NAKAYAMA, S., IWASAKI, M. and OKAMOTO, H. (2006). Frizzled3a and Celsr2 function in the neuroepithelium to regulate migration of facial motor neurons in the developing zebrafish hindbrain. Development 133: 4749-4759.

WAGNER, D. S., DOSCH, R., MINTZER, K. A., WIEMELT, A. P. and MULLINS, M. C. (2004). Maternal control of development at the midblastula transition and beyond: Mutants from the zebrafish II. Dev Cel/6: 781-790.

WARGA, R. M. and KIMMEL, C. B. (1990). Cell movements during epiboly and gastrulation in zebrafish. Development 108: 569-580.

WEBB, S. E. and MILLER, A. L. (2006). Ca2+ signaling and early embryonic 
patterning during the blastula and gastrula periods of zebrafish and Xenopus development. Biochim Biophys Acta 1763: 1192-1208.

WILKINS, S. J., YOONG, S., VERKADE, H., MIZOGUCHI, T., PLOWMAN, S. J., HANCOCK, J. F., KIKUCHI, Y., HEATH, J. K. and PERKINS, A. C. (2008). Mtx2 directs zebrafish morphogenetic movements during epiboly by regulating microfilament formation. Dev Bio/314: 12-22.

WILLIAMS-MASSON, E. M., MALIK, A. N. and HARDIN, J. (1997). An actinmediated two-step mechanism is required for ventral enclosure of the $\mathrm{C}$. elegans hypodermis. Development 124: 2889-2901.

WILSON, E. T., CRETEKOS, C. J. and HELDE, K. A. (1995). Cell mixing during early epiboly in the zebrafish embryo. Dev Genet 17: 6-15.
YANG, C., CZECH, L., GERBOTH, S., KOJIMA, S. I., SCITA, G. and SVITKINA, T (2007). Novel roles of formin $\mathrm{mDia} 2$ in lamellipodia and filopodia formation in motile cells. PLOS Bio/5: 2624-2645.

YASUDA, S., TANAKA, H., SUGIURA, H., OKAMURA, K., SAKAGUCHI, T., TRAN, U., TAKEMIYA, T., MIZOGUCHI, A., YAGITA, Y., SAKURAI, T. et al. (2007). Activity-induced protocadherin arcadlin regulates dendritic spine number by triggering $\mathrm{N}$-cadherin endocytosis via TAO2beta and p38 MAP kinases. Neuron 56: 456-471

ZALIK, S. E., LEWANDOWSKI, E., KAM, Z. and GEIGER, B. (1999). Cell adhesion and the actin cytoskeleton of the enveloping layer in the zebrafish embryo during epiboly. Biochem Cel/ Bio/77: 527-542.

\section{Further Related Reading, published previously in the Int. J. Dev. Biol.}

See our recent Special Issue Placenta edited by Joan S. Hunt and Kent L. Thornburg at: http://www.ijdb.ehu.es/web/contents.php?vol=54\&issue=2-3

Identification of hoxb1b downstream genes: hoxb1b as a regulatory factor controlling transcriptional networks and cell movement during zebrafish gastrulation.

Willem M.R. van den Akker, Antony J. Durston and Herman P. Spaink

Int. J. Dev. Biol. (2010) 54: 55-62

Characterization of the functional properties of the neuroectoderm in mouse Cripto -/embryos showing severe gastrulation defects.

Giovanna L. Liguori, Diego Echevarria, Sonia Bonilla, Daniela D'Andrea, Annamaria Liguoro, Maria G. Persico, and Salvador Martinez

Int. J. Dev. Biol. (2009) 53: 549-557

Geometry and mechanics of teleost gastrulation and the formation of primary embryonic axes.

Elena M. Cherdantseva and Vladimir G. Cherdantsev

Int. J. Dev. Biol. (2006) 50: 157-168

Gastrulation in amphibian embryos, regarded as a succession of biomechanical feedback events.

Lev V. Beloussov, Natalia N. Luchinskaya, Alexander S. Ermakov and Nadezhda S. Glagoleva Int. J. Dev. Biol. (2006) 50: 113-122

Sodium ions affect axis formation and epiboly in fish embryos.

A A Minin and I P Ivanova

Int. J. Dev. Biol. (1996) 40: S233-S234

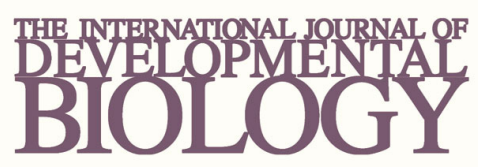

Volume 54 Nos. 6/7

Special Issue

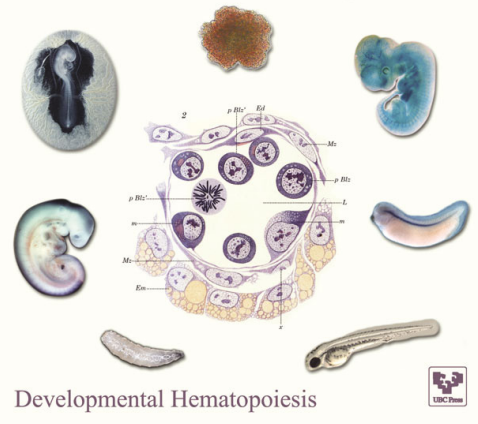

5 yr ISI Impact Factor $(2009)=3.253$

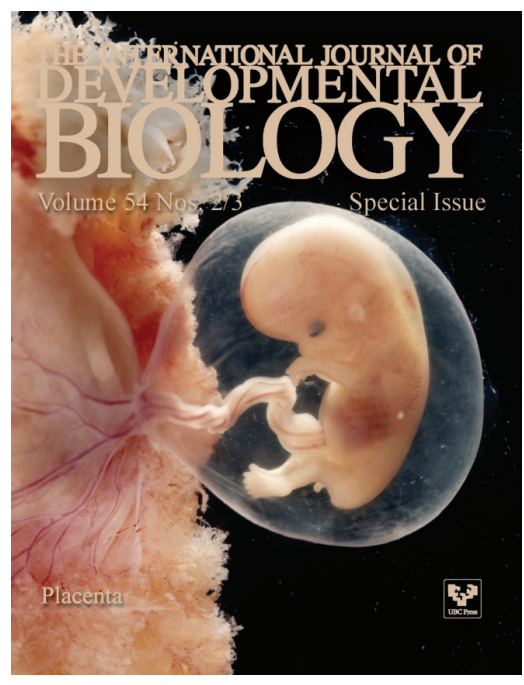

